\title{
Personality and Longevity: Knowns, Unknowns, and Implications for Public Health and Personalized Medicine
}

\author{
Benjamin P. Chapman, ${ }^{1}$ Brent Roberts, ${ }^{2}$ and Paul Duberstein ${ }^{1}$ \\ ${ }^{1}$ Laboratory of Personality and Development and Rochester Health Decision Making Group, Department of Psychiatry, \\ University of Rochester Medical Center, 300 Crittenden, Rochester, NY 14607, USA \\ ${ }^{2}$ Personality Interest Group, Department of Psychology, University of Illinoi, Rochester, NY 14607, USA
}

Correspondence should be addressed to Benjamin P. Chapman, Ben_Chapman@URMC.Rochester.edu

Received 31 March 2011; Accepted 19 May 2011

Academic Editor: Bo A. Hagberg

Copyright (๑) 2011 Benjamin P. Chapman et al. This is an open access article distributed under the Creative Commons Attribution License, which permits unrestricted use, distribution, and reproduction in any medium, provided the original work is properly cited.

\begin{abstract}
We review evidence for links between personality traits and longevity. We provide an overview of personality for health scientists, using the primary organizing framework used in the study of personality and longevity. We then review data on various aspects of personality linked to longevity. In general, there is good evidence that higher level of conscientiousness and lower levels of hostility and Type D or "distressed" personality are associated with greater longevity. Limited evidence suggests that extraversion, openness, perceived control, and low levels of emotional suppression may be associated with longer lifespan. Findings regarding neuroticism are mixed, supporting the notion that many component(s) of neuroticism detract from life expectancy, but some components at some levels may be healthy or protective. Overall, evidence suggests various personality traits are significant predictors of longevity and points to several promising directions for further study. We conclude by discussing the implications of these links for epidemiologic research and personalized medicine and lay out a translational research agenda for integrating the psychology of individual differences into public health and medicine.
\end{abstract}

\section{Introduction}

The notion that personality and health are linked dates back to Galen [1]. In this paper, we review evidence on associations between personality traits and longevity. The first section provides a conceptual and definitional overview of personality for health scientists not familiar with personality research. Section 2 articulates a basic framework and rationale motivating studies of personality and longevity. Section 3 reviews the data on personality and longevity. Section 4 explains the implications of this literature for understanding and promoting healthy aging and provides a road map for future research spanning psychology and health.

\section{Brief Overview of Personality for Aging Researchers and Health Scientists}

2.1. Personality Traits. Personality traits reflect distinct sets of interrelated thoughts, feelings, and behaviors [2]. This is a fairly broad definition, and for this reason, personality has been called "the last refuge of the generalist in psychology" [3]. Personality traits are typically operationalized as dimensions, ranging from very high to very low $[4,5]$. This is in contrast to a present/absent definition of a trait in, for instance, Mendelian genetics. For instance, extraversion is a personality dimension reflecting sociability, excitement seeking, and a generally consistent positive outlook. A person may possess a relatively high amount of extraversion, a moderate amount, a low amount, or anywhere in between these designations. Operationalizing traits as dimensions provide more nuanced information about people than a crude present/absent designation.

Personality traits are relatively consistent, in the sense that people do not change radically from one day to the next. However, change does occur over the long term, due either to naturalistic forces, such as physiological aging, or to due to intentional intervention [6-8]. Thus, personality represents a core of relatively stable individual differences in which alterations can be intentionally induced or can occur 
naturalistically. Personality traits are considered phenotypic dimensions of human variation, reflecting both genetic and environmental influences. Twin studies converge on heritability estimates of major personality traits ranging from $40-50 \%$, with most of the remainder of variation attributable to nonshared environmental influences [9].

Although a few candidate genes are beginning to be identified for personality traits $[10,11]$, Genome Wide Association Studies (GWAS) have yielded scant findings because personality traits are presumed to be polygenic: they reflect complex interactions between specific genes, rather than the presence of a single gene $[12,13]$. This requires more complex analytic models than have been employed to date in molecular genetic studies of personality. Moreover, personality traits are the product of unknown, but probably large degrees of gene-environment interaction [9, 14]. Few studies, even those with GWAS data, include a comprehensive battery of life history and environmental events and exposures. Without this data, it is impossible to identify the environmental conditions under which specific genes may be linked to personality phenotype. As a result, current understanding of personality genetics rests primarily on heritability estimates from twin studies. To the extent that GWAS studies can identify the polygenic and geneticenvironmental interfaces underlying phenotypic traits, they will refine understanding of the genetic bases of personality.

A final important piece of personality science includes the measurement of personality traits. Measurement can use self-report inventories containing written questions reflecting specific traits, similar inventories completed by others who know the person, behavioral measures such as the frequency with which one performs various acts, freeresponse tests where people are asked to provide stories or descriptions of visual stimuli, nonverbal tests in which people report the extent to which pictures describing various personality tendencies describe them, physiological measures such as how reactive a person is to a stressful stimulus, or tests of ability such as a person's capacity to inhibit impulsive responding, resist a temptation, or accurately recognize a facial expression of emotion [15]. In practice, self-report inventories developed through psychometric methods are the most common form of measurement.

Many investigators are taught to distrust self-report as a general measurement strategies because it may be inaccurate [16]. Yet self-reported personality data tends to be accurate and is also more trustworthy than self-reported biomedical data or observer reports of personality. Relatively sophisticated methods have been developed to assess whether a respondent is intentionally dissembling in their response, is trying to be honest but merely has an unrealistically positive self-perception, is responding randomly or haphazardly to questions, merely agreeing with every statement put before them, or engaging in some other behavior that biases measurement [15]. Self-report is more liable to be untrustworthy when respondents are asked to report biomedical data, such as disease exposure or disease diagnoses they may not fully understand. Self-report bias is also more active in "high stakes testing" situations where incentives exist to misrepresent oneself, such as when undergoing a mental health, forensic, injury/disability, or occupational assessment $[17,18]$. In contrast, personality instruments ask innocuous questions about the person's daily habits, which people typically know and are able to report accurately, without the bias that occurs when sensitive questions are posed $[19,20]$.

Self-report is often preferred over observer ratings of personality $[21,22]$ because observers do not have access to a person's internal motives, emotions, thoughts, and so forth-only to external behavioral manifestations of these. Even then, they are not at the individual's side for extended periods and only observe his or her behavior in certain situations. Only the respondent him or herself is qualified to provide data on his or her own inner tendencies and behavior across all situations over extended periods of time. Other evidence suggests that reporting bias has minimal impact on the prediction of important outcomes [23], and that the tendency to present oneself in a positive light is a personality trait itself $[24,25]$. For these reasons, selfreport has been the primary mode of personality assessment in studies on personality and longevity. Nevertheless, personality researchers are increasingly considering how to incorporate other measurement methods, such as informant reports, into personality assessment in health research.

\section{Approaches to the Study of Personality and Longevity}

3.1. Conceptual Framework for Personality and Longevity. Figure 1 summarizes a heuristic model of the ways in which personality is thought to affect longevity $[26,27]$. Behavioral causes of mortality, including smoking, diet, exercise, alcohol use, and risk-taking are all linked to basic personality dispositions [28]. Less obvious factors such as health decisionmaking styles [29] and health risk evaluation [30, 31] have also been linked to personality, as have psychopathology $[32,33]$ and social relationships [34]. Personality appears to influence health through biological channels as well. Characteristic emotional patterns have been linked to neuro-endocrine interactions involving the HypothalamicPituitary-Adrenal (HPA) and Sympatho-Medullary (SAM) axes $[35,36]$. Common genetic bases may also lead to the joint expression of certain personality phenotypes, problematic health behaviors, and resulting chronic diseases [37].

The extent to which any particular mediator affects personality-mortality associations is likely to depend on the personality trait, the form of mortality, and the population.

As denoted in Figure 1, personality traits act on health in social contexts [38]. Personality development is influenced by social-environmental factors such as socioeconomic status (SES) $[39,40]$. As well, personality traits can lead to selfselection into different environments [41] and differential responses to socioeconomic disadvantage [40]. As a result, personality-health relations are at least somewhat intertwined with social forces that influence longevity. The role of social inequalities in health is rarely a focus in personality and health research, but in Section 4 we outline three possible models for future investigation. 
3.2. The Big 5 Taxonomy and General versus Specific Trait Approaches to Longevity. Because there are thousands of words in natural language used to denote personality traits, personality scientists have developed a taxonomy for organizing and classifying them. This taxonomy consists of 5 general axes representing the primary dimensions of human personality variation [4]. These so called "Big 5" axes are Neuroticism versus Emotional Stability, Extraversion versus Introversion, Openness to Experience versus Closedness, Agreeableness versus Antagonism, and Conscientiousness versus Irresponsibility. The Big 5 dimensions are composites, or clusters of numerous "building block" traits (Figure 2). It is helpful to think of the Big 5 as the primary "molecules" of personality, each molecule composed of the "atoms" of specific traits. The lexical hypothesis suggests that the Big 5 reflect basic tendencies of such sociocultural significance that they have become encoded in human languages [4]. Recent work suggests a biological basis for this trait taxonomy as well [42]. Finally, the term "Five-Factor Model" is often used to denote the Big 5 in personality psychology [43]. Minor differences between what each term connotes are of interest to personality scientists, but are not important here.

Because the Big 5 are composites of several specific traits, these measures capture an amalgam of numerous specific facets of personality. The advantage of using a composite measure aggregating each family of traits is that it increases the likelihood that some aspect(s) of personality relevant to health have been captured by scores on Big 5 measure. The downside is that unless this composite measure of the entire trait "molecule" can be disaggregated into the specific constituent "atoms", investigators cannot isolate the component(s) of personality most relevant to longevity.

By contrast, another approach to personality and longevity has focused more directly on the specific traits lying within each Big 5 domain. The Big 5 taxonomy did not begin to be used extensively in health research until the early 1990s [44]. Prior to the 1990s, investigators had no choice but to select single traits they believed were associated with mortality. Other investigators preferred this selective, specific approach to personality and longevity even after the Big 5 system had become the major framework in personality research. One reason is that some theoretical traditions within psychology stress the importance of specific traitsfor instance, emotional suppression in psychodynamic theory [45] has no obvious analogue in natural language or the Big 5. Another reason some investigators prefer specific traits is that occasionally, a particular trait is not formally measured by the Big 5 system. For instance, sensuality, religiosity, masculinity-femininity, and thriftiness/miserliness versus prodigality have been argued to lay outside of the Big 5 domains [46]. Despite the broad consensus surrounding the Big 5, other investigators continue to examine the constituent components of the domains outside the Big 5 framework. Examples include hostility in interpersonal theory [47], or constructs related to personal control in control theory [48].

The advantage of focusing on specific traits is that they implicate very particular aspects of personality in longevity, providing more precise information for theory and intervention. A disadvantage is that there may be many other specific traits that are relevant to longevity which are omitted from these studies. These traits may be confounders or even interact with the specific trait in question, because all aspects of personality are in simultaneous function in everyday life. The problem is analogous to examining healthrelated outcomes only as a function of smoking, without considering diet, exercise, alcohol, environmental exposures, health service utilization, medication adherence, or dozens of other behavioral predictors of health outcomes that may themselves be related smoking.

Despite the difference in research motivated by a Big 5 , versus specific trait model, it is still possible to organized findings within the Big 5 framework. In the presentation that follows, we group specific traits under the Big 5 taxonomic dimension in which they are primarily classified. For instance, optimism is classified as a trait in the Extraversion domain of traits. However, some of these specific traits may have secondary classification under another Big 5 dimension. For example, (low) optimism/pessimism is sometimes considered to lie secondarily within the Neuroticism domain. One can think of such "cross-classified" traits as sharing some characteristics of more than one Big 5 domain, or laying at the intersection of Big 5 domains. Full listings of Big 5 traits can be found in [49]. A similar idea is the concept of a "compound trait" [50], or a combination of two or more specific traits, often spanning Big 5 dimensions. In later sections, we also discuss the notion of personality prototypes [51] and styles [52], which refer to specific profiles or configurations of the Big 5 dimensions. In conceptualizing factors that enhance or reduce longevity, we also differentiate between all-cause mortality, and cardiovascular disease(CVD) related and cancer mortality when possible. The CVD versus cancer classification is a common one in epidemiologic studies. Each class contains several diseases unified by a common set of etiologies, and in some cases the personality traits have been implicated more in one set of etiologic processes than another.

\section{Evidence Linking the Big 5 Personality Dimensions to Longevity}

4.1. Conscientiousness. Conscientiousness involves self-discipline, achievement striving, reliability, and several similar traits related to diligence [53]. This Big 5 dimension has been linked to lower all-cause mortality risk across a number of studies [54-57] (see also [58]). The strength of associations between Conscientiousness and longevity appears comparable to those between longevity and SES and IQ [59]. Conscientiousness appears to be the one Big 5 domain for which no negative results exist. However, some pathologies of Conscientiousness such as perfectionism or compulsive persistence should be noted. In one study, the all-cause mortality risk of Conscientiousness was modeled controlling for perfectionism, [56]. In this case, Conscientiousness was associated with reduced, while perfectionism was associated with increased risk. Immunologic work has suggested that compulsive persistence, defined as the inability to disengage from an impossible, stressful task, induces higher HPA-axis response [60]. It is thus helpful to differentiate "healthy" 


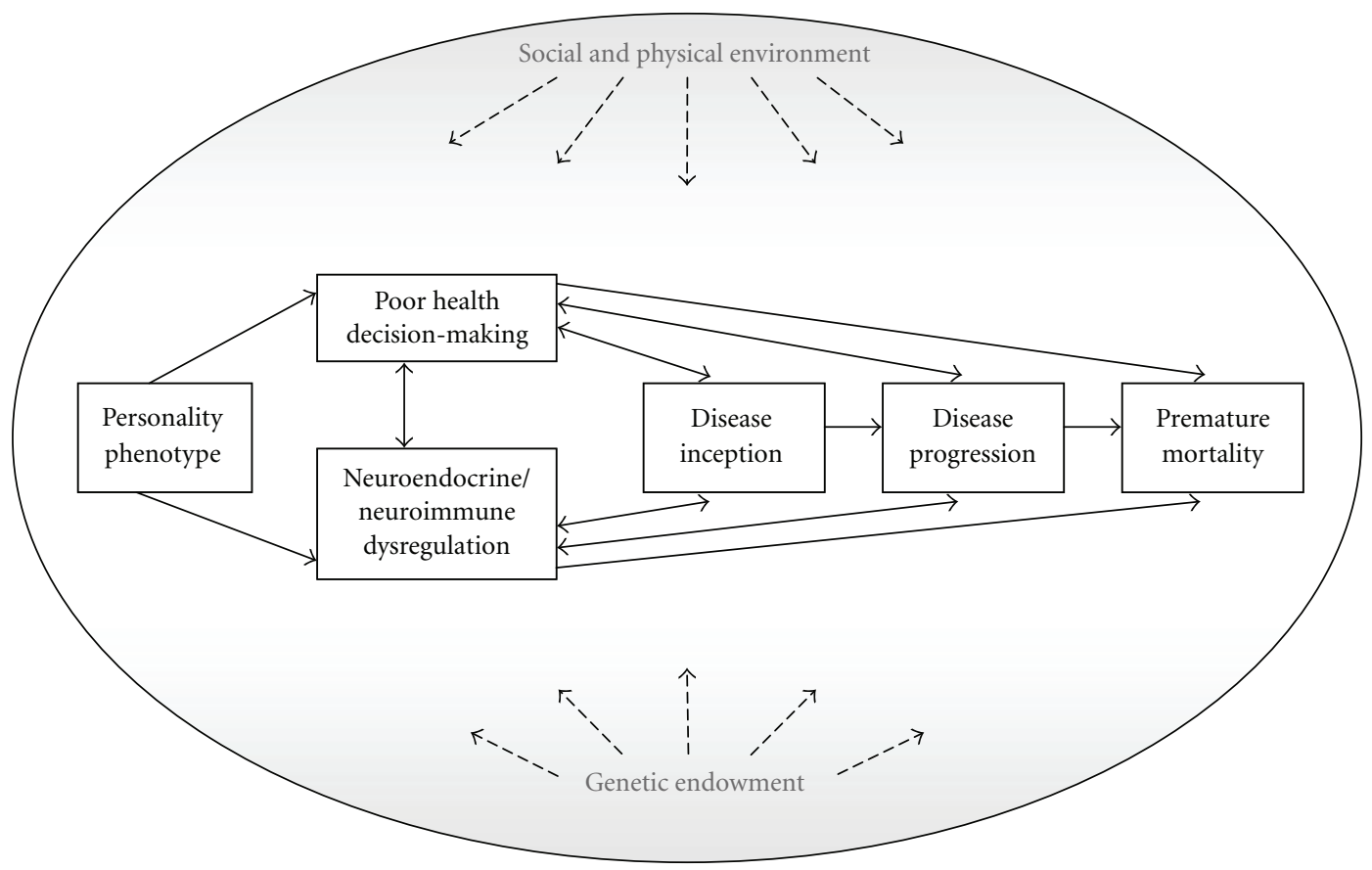

FIGURE 1: Personality phenotype is thought to influence longevity through physiological and behavioral pathways leading to health decline. This occurs in the context of environmental (physical or social) and individual genetic influences, which may enter into risk chains directly or modify them indirectly.

Conscientiousness from extreme rigidity or compulsion. Conscientiousness involves a strong self-regulatory component, which facilitates adaptive outcomes [61] in part by preventing inflexibility like perfectionism or compulsive behavior.

Because of the self-discipline it entails, Conscientiousness has been linked to a variety of health behaviors including maintaining healthy activity and diet, and abstaining from smoking, alcohol, and substance abuse [28]. However, links between Conscientiousness and longevity are only partly explained by commonly studied health behaviors [62-64]. Less frequently studied health behaviors, such as health decision-making and risky sexual practices, are avenues for further investigation. Biological mechanisms are not well understood, but seem to be implicated in the Conscientiousness-longevity link if only because health behaviors generally account for a surprisingly small portion of the observed association. For instance, higher levels of the inflammatory marker Interleukin (IL)-6 have recently been linked to lower Conscientiousness $[65,66]$. IL-6 is associated with chronic stress, a number of chronic diseases, and negative health behaviors, and is a major predictor of mortality in older persons $[67,68]$. Studies showing higher IL-6 linked to lower Conscientiousness have controlled, however, for health behaviors and chronic diseases, so a working hypothesis is that Conscientious people are better able to anticipate and prepare for future consequences of potential adversities, more organized, and self-disciplined. These qualities could prevent stressful situations from escalating and could also enhance coping.

Several areas of new research are emerging based on the initial wave of studies linking higher $\mathrm{C}$ to longevity. A recent National Institute on Aging workgroup has offered a series of recommendations for advancing research on Conscientiousness, including refining its biological basis and measurement, considering how this trait operates on health in different social contexts, articulating better lifespan models of the effects of Conscientiousness, and intervening in specific areas such as self-regulatory skills. White papers in these areas are due out later in 2011.

4.2. Openness to Experience. Although there is minor disagreement over the range of traits belonging in the Openness to Experience domain, most agree that Openness encompasses cognitive and behavioral flexibility, urbane or cultured tendencies, and attunement to internal and external events and experiences [69]. Although it may reflect a propensity toward an intellectual lifestyle in certain cultures, it is distinct from raw intellectual ability [70] and in fact is observable in nonhuman primates [71]. Higher levels of Openness have been associated with decreased risk for all-cause mortality in a Japanese community sample [54], with lower risk of allcause and CVD mortality in an American sample of CVD patients [72], and with lower all-cause mortality risk in a cohort of men [73]. The latter two studies were able to decompose Openness into more specific traits and found that cognitive and behavioral flexibility [72] and interest in aesthetics $[72,73]$ were particularly important predictors of greater longevity. Reduced 5-year all-cause mortality risk has also been documented for curiosity, a facet of Openness, in a mixed-gender older community sample [74]. Finally, one study reported nonsignificant decreases in all-cause mortality risk associated with the general Openness domain [56]. 
The mechanisms by which Openness may improve longevity are not immediately clear. Beyond basic genetic influences, others factors may include cognitive engagement, flexibility, and the maintenance of cognitive function [75]. These factors probably facilitate the prevention of avoidable health problems, as well as increase adaptive disclosure of health concerns, health decision-making, and capacity to manage problems that are encountered. As with other traits, investigators have begun to examine inflammatory markers as a general biological mechanism accounting for health benefits of Openness. One study found that higher Openness was linked to lower levels of the inflammatory marker Interleukin-6 in older persons [66]. Another possibility is that Openness may be related to markers of synaptic plasticity, such as Insulin-Like Growth Factor (IGF)-1, which has been linked to cognitive function and longevity [76]. In general, the associations between Openness associations with longevity seem to be distinct from the effects of education, which is typically controlled for in analyses. However, few studies to date have investigated the distinct longevity associations for Openness and IQ. This will be an important area for future work.

\subsection{Extraversion}

4.3.1. The General Extraversion Domain. Extraversion is another broad dimension of personality appearing in some form in most personality trait theories [42]. Extraversion encompasses the tendency toward positive mood, sociability, and activity (in the sense of an active, busy, or engaged lifestyle) [77]. As well, it involves an element of excitement seeking or social disinhibition. This last aspect of Extraversion tended to be very prevalent in an earlier operationalizations of Extraversion [78]. In the Big 5 framework, the desire for excitement is still a part of Extraversion, but pure impulsivity and low self-control are captured by Neuroticism (high) and Conscientiousness (low) [79]. This is relevant to longevity because early Extraversion scales loaded with impulsive content predicted greater all-cause mortality risk over 21 years in a large UK cohort [80] (see also [81]). This effect was accounted for in part by smoking, a health behavior to which more Extraverted people appear susceptible, regardless of whether older or new operationalizations of Extraversion are used [82-85].

Focusing more on elements such as sociability and positive mood, modern operationalizations of Extraversion, tend to find that it is associated with reduced all-cause mortality risk. This was the case over a 9-year followup period in an American [56] community sample, a 5-year follow-up period in a Japanese [54] community samples, and a 6-year follow-up in an older twin sample [87]. The activity facet of Extraversion has also been associated with lower 50 -year all-cause mortality risk in a US cohort [88], with suggestive findings over 10 years in another US cohort [62]. Other studies noted no substantial effects for the general Extraversion dimension on 3-year all-cause mortality in an older, ill US community sample [63], in substance and alcohol abusers [89], or in Japanese cancer patients (with a general case-mix of cancer types) [90].
These findings provide some limited evidence that in general community samples, higher levels of Extraversion are associated with greater longevity. However, as excitementseeking strays into impulsivity and poor self-control, mortality risk may mount. Null findings in specific samples (the ill elderly, alcohol/substance abusers, cancer patients) and links between Extraversion and smoking suggest that the salutary effects of Extraversion, arising from traits such as sociability, activity, and positive mood, may be overpowered by the mortality risks conferred by physical morbidity or destructive addictive behaviors. Another issue is impulsivity tends to decline with age in most cohorts, in part as a normal function of aging [7], but possibly also because more impulsive members of a cohort die earlier. As a result, impulsivity-related mortality risk may be dampened beyond detectable levels in analyses of older samples.

As a technical note, impulsivity is sometimes classified as a Neuroticism trait on some personality instruments, while similar traits such as self-discipline and deliberation appear in the Conscientiousness family [79]. In this vein, one study found that higher impulsivity in the elderly was actually associated with greater probability of 3-year survival [63]. One possibility is that the speed of action entailed by measures of impulsivity actually relates to processing speed, a neurologic factor argued to reflect general integrity of biologic systems [37]. Possibly this could be better distinguished in personality measurement tools from pure sensation seeking or lack of self-discipline, which have clear deleterious effects on health. Research on performance-based measures of impulsivity and self-report scales reveals low correlations [91], suggesting that better measurement may help refine conceptual models differentiating harmful from helpful aspects of impulsivity/sensation-seeking/low levels of deliberation.

4.3.2. Optimism. Optimism is a stable tendency to expect positive future outcomes, while pessimism is the tendency to expect negative outcomes. Sometimes optimism and pessimism are operationalized as two separate constructs [92], sometimes they are considered opposite ends of a single continuum [93], and academic debates exist over the manner in which optimism is related to the Big 5 [94]. For the sake of clarity and utility in health research, optimismpessimism can safely be considered as a single dimension, defined primarily by high levels of Big 5 Extraversion and secondarily by low levels of Big 5 Neuroticism.

Links between optimism and longevity have been documented in a range of populations. Optimism is associated with lower risk of all-cause mortality over 40 years in both college freshman [95, 96] and over 30 [97] and 40 [96] years in community midlife samples. Short-term $(\leq 1$ year) cancer mortality has also been linked to lower levels of optimism in younger patients with a diverse range of cancers [98], and in head and neck cancer patients [99]. Death over a 10-year span related to CVD disease in men [93] and death due to stroke in a general community sample [100] have also been linked to lower optimism. One study found no effect for optimism but elevated cancer mortality risk related to pessimism when these two constructs were 


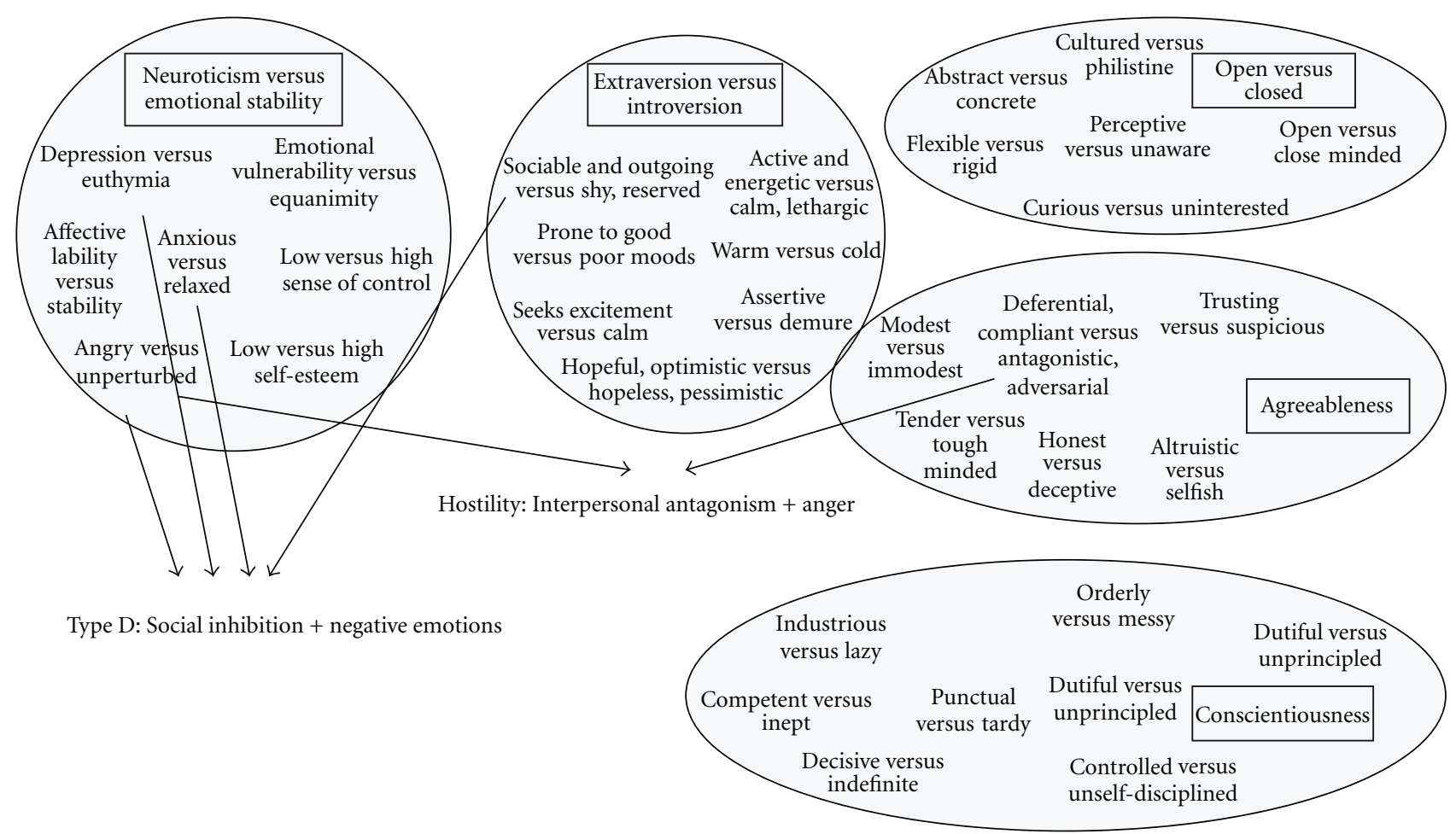

FIGURE 2: An example of specific traits with major loadings on each of the Big 5. In the diagram, the two compound traits studied with respect to longevity, hostility and Type D, are combinations of traits from different Big 5 dimensions. Numerous other traits and combinations exist; see [49] for a comprehensive mapping of specific traits composing each of the Big 5, and [86] for a comprehensive analysis of compound traits composed of 2 Big 5, with a similar perspective also presented in [52].

conceptualized as separate variables [98]. In our more general framework, this distinction is less relevant and favors greater longevity for people who do not expect negative things of the future, controlling for whether or not they have positive expectations.

More adaptive coping has been posited as one mechanism explaining the association of optimism with lower mortality risk [101]. In addition to, or possibly because of the coping advantage it confers, optimism appears linked to lower level of ambulatory blood pressure [102] and lower levels of inflammatory markers [103]. However, mixed evidence has emerged on the association of optimism with immune function, with one hypothesis being that optimists may experience more frustration when they do not experience immediate success and/or persist longer in stressful situations because they expect positive results [60, 104-106]. Another hint that optimism may not always be adaptive appeared in a study of high IQ children, which found that cheerfulness, defined as optimism and sense of humor, predicts greater mortality risk by midlife. The extent to whether these traits in children measure something similar to adult optimism is not clear, however. While these studies provide some hint that optimism may be maladaptive in some contexts, the preponderance of evidence to date suggests that it tends to promote lower mortality risk in most people in most circumstances.

\subsection{The Neuroticism Domain}

4.4.1. Findings on Broad Neuroticism. Neuroticism is a dimension of personality present not only in the Big 5 framework, but in nearly every other empirically based personality trait theory [42]. The definition of the Neuroticism domain has subtly shifted over time. Prior to the Big 5 framework, Eysenck primarily defined Neuroticism according to stressreactivity and emotional lability, with some items that could be interpreted as somatization or somatic sensitivity [107]. The instability component was retained in Big 5 notions of Neuroticism [49], with some emphasizing the chronic experience of specific negative emotions such as anxiety, depression, and anger [79]. Another aspect of Neuroticism that is often neglected is vulnerability, or a sense that one is unable to cope with the challenges of life. This is partially related in the concept of emotional instability, and reflected in items like "I seem to go to pieces easily." It is for this reason that many of the traits related to feeling a sense of control over one's life reflect low Neuroticism. For instance, the correlations between locus of control, self-esteem, and selfefficacy with Neuroticism appear so strong across samples that these traits can essentially be considered aspects of Neuroticism [108].

With respect to health behaviors, elevated has been linked to weight gain and obesity [84, 109] and smoking [110], 
general etiologic factors in foreshortened longevity. In fact, Neuroticism has been argued to be of general public health significance because it is associated with so many negative outcomes $[111,112]$.

Several studies have linked higher Neuroticism to allcause mortality in general populations from the US [62], Finland [113], and the United Kingdom [80, 81] over as long a follow-up period as 50 years $[88,113]$, as well as in an older twin sample [87]. As well, higher levels of Neuroticism predicted mortality risk in specific patient populations such as those with end-stage renal disease (ESRD) [57] and congestive heart failure (CHF) [114]. Naturalistic increases over time in Neuroticism have been linked to later allcause mortality in a sample of older American men [115]. Treatment-induced decreases in Neuroticism also reduced risk of mortality over 9 years in European patients with cardiovascular disease (CVD) [116]. Finally, at least two studies have noted some confounding between socioeconomic status (SES) and Neuroticism, such that some of the socioeconomic inequalities in mortality rate can actually be explained by the fact that persons in more disadvantaged social environments are prone to higher Neuroticism $[62,113]$.

Other studies have reported negative findings. No associations between Neuroticism and all-cause mortality were observed in US [117] and Japanese [54] community samples. The same was true with respect to cardiovascular disease (CVD) mortality in a US community sample [117] and with respect to cancer mortality in a sample of Japanese cancer patients [90]. Another study reported no association between elevated Neuroticism and increased all-cause mortality risk in a female community sample [118]. However, in a sample of gifted individuals, elevated Neuroticism was linked to lower all-cause mortality risk in women but higher mortality risk in men [119]. To complicate the picture further, two studies have found that higher Neuroticism was associated with reduced all-cause mortality risk in mixed-gender older community samples in the US [63] and Australia [120].

What, then, is one to think of the implications of Neuroticism for longevity? Friedman has proposed a theory of "healthy" versus unhealthy Neuroticism [26]. "Healthy neuroticism" encompasses "worried well" tendencies that may facilitate engagement in preventive health behavior to allay concern about acquiring chronic health problems. Healthy Neuroticism may be represented by individuals higher in anxiety, but not laden by poor self-esteem, vulnerability, and depressive moods. Neuroticism gives rise to medically unfounded symptom complaints and somatic sensitivity $[118,121]$, which may protect an individual from premature mortality even though it risks burdening health care providers and the health care system. However, Neuroticism has been linked to reduced quality of life [122], even controlling for objective measures of disease load [123] raising the question of whether higher levels lead to more quality-adjusted life years. Clarifying the mortality risk of Neuroticism is an important research priority we discuss in the next section.

4.4.2. Low Perceived Control. Locus of control, perceived control, self-efficacy, and sense of coherence are a group of interrelated psychological constructs reflecting the extent to which people feel in control or are able to deal with life stressors and challenges. As suggested by their high loading on the Big 5 Neuroticism dimension [108], these constructs are trait-like, even though they were developed by researchers who were less concerned with stable traits. Although "sense of coherence" suggests existential congruence between one's behavior and one's goals, the construct is really closer to perceptions of control over one's life [124]. In general, this family of traits is theorized to improve adaptation to hardship or life challenges via the use of proactive, effective coping [125].

The range of findings generally suggests that these dispositions are associated with greater longevity. In a large British national cohort, lower mastery was a risk factor for all-cause, CVD, and cancer death over 6 years [126] and for CVD mortality over 11 years, particularly in persons with low CVD risk $[127,128]$. In this UK cohort, the same pattern of findings emerged for those with low sense of coherence, although this trait was a risk for cancer mortality only in men [128]. Similar findings for all-cause mortality have been reported in a Finnish cohorts [129], and for CVD mortality in a German cohort [130]. Sense of coherence appears to produce more adaptive coping in response to life stressors, which was in turn associated with lower mortality risk [125]. In general, recent research supports the adaptive value of perceived control [131], although not inexorably under all conditions [132].

4.4.3. Negative Affect Blended with Social Inhibition: The Type D Personality. “Type D" stands for the distressed personality, defined by simultaneously high negative affect and social inhibition [133]. It represents high levels of Big 5 Neuroticism, coupled with low levels of the sociability facet of Big 5 Extraversion, with some suggestion of accompanying declivity in Agreeableness and Conscientiousness [134, 135]. Conceptually, Type D has been described as a general propensity toward psychological distress, encompassed by depression, anxiety, and other forms of negative emotion, such as anger $[136,137]$, and combined with inadequate social resources to offset this distress [138]. This personality configuration was originally identified empirically as a predictor of all-cause mortality over 7.5 years in a sample of CVD patients [139].

Subsequent reports have shown that Type D also increases risk of mortality in CVD patients two years after receiving stents [140], over 2.5 years in patients with chronic heart failure (CHF) [141], over 4 years in peripheral artery disease $(\mathrm{PAD})$ patients who underwent vascular surgery [142], and over 6 years in coronary artery disease (CAD) patients [143]. The majority of mortality in these studies was due to cardiovascular factors. However, negative findings have been reported for all-cause and cardiovascular mortality over 3 years in CVD patients [144], and for 7-year all-cause mortality in patients with chronic obstructive pulmonary disease (COPD) [145]. These latter two studies reported small to modest elevations in mortality risk for Type D that were not statistically significant. 
Taken as a whole, these findings indicate that Type D conveys mortality risk in those with or at risk for various forms of CVD. Type D acts through many behavioral risk factors for the inception and progression of CVD, including maintaining a poor diet and smoking [146]. As well, Type D is associated with inflammatory markers [147150] and oxidative stress [151], which both contribute to the progression of CVD. Others studies suggest that anxiety, associated with sympathetic nervous system disturbance [152], as well as ineffective interaction with health care providers [153], contributes to Type D-related mortality risk. While many studies have documented poorer general health correlates of Type D in community (rather than CVD) samples $[154,155]$, the risk posed by Type D for mortality due to non-CVD causes, in nonpatient samples, remains to be elaborated. Finally, Type D is a risk factor for depressive episodes, which are thought to dampen prognosis of CVD via inflammation and neglectful health behavior $[137,156]$.

4.4.4. The Distinction between Neuroticism and Depression. A final note on the relationships between Neuroticism (or other aspects of personality) and depression (or other aspects of psychopathology) is in order. Depression is a particular form of psychopathology considered related to, but distinct from personality. Personality is relatively stable, while depression is defined as an episodic cluster of symptoms reflecting a change in mood and function from a person's normal baseline. Personality refers to the person's "normal baseline". People who are routinely prone to negative emotions and emotionally unstable may be more likely to develop depressed mood, the first cardinal symptom of depression [157]. People who rarely experience positive emotions (an aspect of low Extraversion) may be more liable to experience virtual absence of pleasure or interest, which is the second cardinal symptom of depression. Those who are prone to negative emotion and socially inhibited (the Type D configuration) are similarly prone to develop formal depression syndromes. Other symptoms of depression, such as anergia, may be more liable to emerge given certain personality vulnerabilities, such as low Extraversion. Under this model, the personality predisposition precedes a diagnosis and persists after the depressive symptoms have been treated, in the same way that a compromised immune system precedes the inception of an opportunistic infection and remains after the infection has been treated. Just as the immune system itself can be treated, there is some evidence that Neuroticism can be as well; we consider this in the next section.

4.5. Agreeableness. Agreeableness is a composite of several traits related to maintaining interpersonal harmony: trust, honesty, compliance, interpersonal deference, altruism, and compassion for others [79]. One study to date has demonstrated a protective effect for Agreeableness against allcause mortality over 3 years in an elderly sample; this was due primarily to specific aspects of the Agreeableness scale reflecting low levels of interpersonal antagonism [63]. We discuss this in detail below when we consider studies focusing specifically on hostility, which involves a combination of low agreeableness and high Neuroticism. Agreeableness did not appear as a robust predictor of longevity in four other studies [54-57]. One study actually found agreeableness was associated with greater 10-year all-cause mortality in a US national cohort, when combined with low Conscientiousness [62]. This study used a different measure of agreeableness focusing on compassion and caring. Collectively, evidence that Agreeableness in and of itself promotes or detracts from longevity is not strong. However, one aspect of low agreeableness - interpersonal antagonism-in conjunction with angry emotions, a facet of Neuroticism, yields the personality trait of hostility, which has been a topic of considerable research.

4.5.1. Hostility. Research on hostility and longevity grew out of the theory of Type A personality. This theory was first introduced by a cardiologist in the 1950s and proposed that the combination of impatience, hard-driving, competitiveness, and hostility was associated with cardiovascular disease (CVD) [158]. However, in the early 1980s investigators began to study hostility in particular $[159,160]$, concluding that it was the primary "toxic" component of the Type A personality $[161,162]$.

Within US samples, hostility appeared to elevate risk for 25-year all-cause mortality among male medical students [159], for 10-year all-cause, CVD, and cancer mortality among midlife men [160], for worse health trajectories involving earlier mortality in male veterans [163]. Hostility also conferred 3-year CVD and all-cause mortality in midlife Finnish men [164], elevated 25-year all-cause mortality in a mixed-gender midlife sample in Denmark [165], elevated 6year CVD mortality [166], and 16-year all-cause mortality, [167] in mixed-gender community samples, the latter even with mean ages below 30 at baseline. Others found that hostility was not associated with CVD risk or 25-year allcause mortality in male physicians [168], with 33-year risk for mortality from any cause among a sample of 19-year olds [169], or with 5-year [170] or 1-year [171] mortality in CVD patient samples. Another sample following postmenopausal women for 4 years found that hostility was associated with recurrent nonfatal myocardial infarctions, but not CVD mortality risk [172].

These discrepancies were largely reconciled when investigators decomposed hostility into 6 components and found that only some were predictive of earlier mortality. In particular, aggressive responding, hostile affect, and cynicism predicted nearly 30-year all-cause mortality in lawyers, while hostile attributions, social avoidance, and "other" hostile items did not [173]. Supporting this were studies linking follow-up mortality in mixed-gender older samples to suspiciousness [174], which is similar to cynicism, and to social dominance in men (defined by cutting off and speaking over an interviewer) [175], which is similar to aggressive responding. When revised scales focusing on these components were utilized, they predicted 15-year CVD mortality in CVD patients [176] and all-cause and CVD mortality in other large cohorts [117, 177, 178]. As a result, many have concluded that despite earlier mixed findings, 
hostility defined by cynicism, interpersonal antagonism, and angry affect confers risk for foreshortened lifespan, particularly via CVD death [47]. In the context of the Big 5 taxonomy, hostility may be thought of as a multifaceted trait blending the angry affect component of Neuroticism with the adversarial interpersonal component of low Agreeableness $[161,179]$.

4.6. Suppression and the Grossarth-Maticeck Personality Types. Suppression, sometimes referred to as emotional or anger suppression or antiemotionality, is a tendency to inhibit the expression of anger and negative emotion [45]. This notion arose out of psychodynamic theory. Although psychodynamic theory is primarily concerned with cognition and mental health [180], not physical health, the health correlates of psychodynamic constructs have been examined [181]. Suppression was first identified in a Yugoslavian cohort as predictive of all-cause and CVD death over 10 years, but was particularly predictive of cancer death in a study by Grossarth-Maticeck [45]. Grossarth-Maticeck called this the "cancer prone" personality type and developed several additional personality configurations: rational, CVD prone, antisocial, and healthy. A report linking these personality types with the diseases they were purported to predict incited considerable controversy over the validity of GrossarthMaticeck's data [182]. A review of this debate is beyond the scope of the present paper. However, objections arose over the question of specificity, or the idea that specific personality tendencies are associated with specific diseases processes. Instead, personality was thought to affect a common set of etiologic factors for multiple diseases (i.e., smoking, obesity, and neuroendocrine dysregulation, which are implicated in several disease), which would make it hard to connect specific traits only to certain outcomes. This is generally supported by current understanding of mechanisms linking traits to disease, in Figure 1. However, Figure 1 might also include an arrow directly from personality to disease reflect as-yet unknown mechanisms. To the extent that such mechanisms were trait and disease specific, the so-called "doctrine of specific etiology" would be more plausible.

Nevertheless, subsequent independent research has suggested that some of the Grossarth-Maticeck personality types may play a role in longevity. A study in Japan found that among patients who already had cancer, moderate levels of suppression actually improved survival, compared to low levels [183]. This hints at the possibility that neither extreme (total suppression or failure to suppress any emotions) is salubrious, consistent with other psychological theories on the role of emotional control in general adaptation [184]. Other independent studies have noted deleterious effects of anger suppression on all-cause mortality over 17 years in a community sample $[143,185]$ and over 6 years in CVD patients [143], although one study in a German cohort found no robust effect for anger control after adjusting for locus of control [130]. A systematic review on repression in cancer survival yielded somewhat inconclusive results [186, 187]. A large French study found that both the CVD-prone and antisocial personalities predicted both allcause, cardiovascular, and external-cause (i.e., accidents, homicides) mortality [188]. Ultimately, less is understood about the Grossarth-Maticeck types and how they affect longevity than other personality constructs, due to the earlier controversies surrounding them. Nevertheless, evidence suggests they warrant further consideration as dispositional risks for foreshortened lifespan. Table 1 summarizes the evidence for each personality dimension discussed above.

\section{Next Steps in Translational and Applied Research}

5.1. Beyond the Broad Big 5: Clarifying the Contribution of Specific Personality Traits to Longevity. As we have seen, the Big 5 is a useful taxonomic framework for classifying personality traits and organizing investigations of personality. Yet the Big 5 was designed as a classification system for many personality traits, not as the ultimate level of analysis in personality research. Few biologists, for instance, would stop at grouping animals into reptiles, mammals, birds, and fishmost are interested in questions at lower levels of aggregation in the Linnaean taxonomy. This is the challenge for emerging research on personality and longevity — having spent an era examining the Big 5 themselves, we now need to drill down further to understand exactly what elements of enduring dispositions are associated with greater longevity. This was, in fact, proposed as a general principle of epidemiologic personality research over a decade ago [189], so we are long overdue in putting this idea into practice. How then is one to actually implement this principle in studies?

In some cases, Big 5 instruments come with built-in subscales for specific traits. For instance, the 240 item NEOPersonality Inventory Revised (NEO-PI R) [79] was designed to capture the Big 5 general dimensions, as well as 30 more specific personality traits subordinate to the Big 5 . Far more studies have used abbreviated Big 5 measures, such as the NEO-Five Factor Inventory (NEO-FFI), which was designed originally only to capture the Big 5 broad composites [79]. However, in some cases like the NEO-FFI, subsequent psychometric work identified subscales reflecting specific constituent traits of each of the Big $5[190,191]$ useful in health studies $[66,192]$.

In other instances, one includes a measure of broad personality dimensions that has not yet been disaggregated into more specific traits. In these cases, there are two primary options. The first approach is to use expert knowledge and theory to select items reflecting a specific trait, and combine these items into a scale. Examples of this approach include a scale reflecting lack of self-discipline from items off the impulsiveness, excitement seeking, and low deliberation scales of the NEO-PI R [110], creating a Neuroticism scale from items measuring negative affect on the MMPI [193, 194], and examining discrete emotions using items on the NEO-PI R [195]. A basic test of whether the effort is successful is whether the resulting scales are internally consistent, and whether they are associated with theoretically expected outcomes; auxiliary datasets may be helpful to verify this. For instance, one project developed scales for a number of traits from an interpersonal theory of personality and found that they correlated as expected with scales in an 
TABLE 1: Summary of studies in personality and longevity.

\begin{tabular}{|c|c|c|}
\hline Personality dimension & Summary of findings & $\begin{array}{l}\text { Strength of overall } \\
\text { evidence }\end{array}$ \\
\hline Conscientiousness & Numerous studies report reduced risk of all-cause mortality across diverse samples & Strong \\
\hline Openness & $\begin{array}{l}\text { Fewer studies, but results suggest reduced risk of all-cause and possibly CVD } \\
\text { mortality }\end{array}$ & Modest \\
\hline Extraversion & Results somewhat mixed, with findings of reduced, increased, and no mortality risk & Inconsistent \\
\hline Optimism & $\begin{array}{l}\text { Many studies suggesting reduced risk for all-cause, cardiovascular, and in some } \\
\text { cases cancer mortality }\end{array}$ & Strong \\
\hline Neuroticism & $\begin{array}{l}\text { Some studies report increased, while other report decreased or no risk for all-cause } \\
\text { and CVD mortality }\end{array}$ & Inconsistent \\
\hline Control & Fewer studies, but findings tend to suggest reduced risk of all-cause mortality & Modest \\
\hline Agreeableness & Fewer studies, with no few substantial effects & Weak \\
\hline Hostility & $\begin{array}{l}\text { Many studies, finding increased risk for all-cause and CVD mortality, driven by } \\
\text { interpersonal antagonism and angry emotion }\end{array}$ & Strong \\
\hline Type D & $\begin{array}{l}\text { Modest number of studies in CVD populations, most finding increased CVD } \\
\text { mortality risk }\end{array}$ & Strong \\
\hline Suppression & $\begin{array}{l}\text { Fewer studies, controversial interpretations of data, some studies suggest increased } \\
\text { risk particularly for cancer mortality, others inconclusive }\end{array}$ & Inconsistent \\
\hline
\end{tabular}

auxiliary dataset that were directly designed to capture these traits [196]. A variation of this theoretically driven approach has derived measures of similarity to theoretically important personality profiles or trait configurations, such as Type D or the "undercontrolled" personality, using general Big 5 scales, with good success in identifying personality-health links [51, 197]. Another variant is descriptive categorizations of individuals' standing on combinations of the Big 5 called "styles" [52], although different analytic approaches to this problem exist.

If there is no theory strong enough to suggest good a priori subscales, one may take an empirical approach by using factor analysis or some other sort of multivariate structural technique. Details on the statistical disaggregation of broad personality traits are provided in [198]; once a reliable representation of specific traits has been found, those traits can be examined alone and in conjunction to better understand the elements of a Big 5 dimension driving an outcome. An important note is that modeling the simultaneous effects of several highly correlated facets can create analytic and interpretive challenges. For instance, gregariousness with sociability partialed out or positive affect with optimism partialed out are difficult characteristics to conceptualize, even though they can be statistically created. Thus, researchers who decompose the Big 5 tend to examine each facet separately, or create linear combinations of facets $[63,192]$, in order to isolate personality effects on health. Next, we turn to another intriguing challenge facing researchers: the interface of personality and socioeconomic inequalities in longevity.

5.2. Clarifying the Personality-SES Interface in Longevity. While most of the studies above controlled for education as a proxy measure of SES, very few focused on issues outlined at the end of Section 2 about the role of personality in socioeconomic inequalities in longevity. Personality analyzed outside of social context-or social inequalities analyzed devoid of personal characteristics — provides only one piece of the puzzle of longevity [199]. It is important for personality epidemiology [189], social epidemiology [200], and life course epidemiology [201] to continue building bridges and mounting studies integrating each of their respective foci.

At least three conceptual models may guide this line of research [199, 202]. The compensatory-cumulative model suggests that personality traits may independently add to or detract from mortality risk conferred by disadvantaged social environments, and/or the benefits conferred by social advantage. The indirect selection hypothesis originally suggested that persons with certain characteristic self select into lower SES, meaning health inequalities are an indirect effect of this selection process [203]. More recent formulations of indirect selection have argued that the relationship between personality and socioeconomic circumstances is mutually reinforcing over time and must be viewed as a bidirectional process in which personality and SES mutually reinforce one another over time [62]. As a result, personality may explain some of the social inequalities in longevity. Finally, the selective vulnerability hypothesis suggests that social adversity engenders more health problems in those with vulnerable personality configurations. Each model is presented diagrammatically in Figure 3.

Limited studies on personality, SES, and longevity to date suggest a mild degree of confounding between mortality risk related to Neuroticism and low control, and mortality risk related to low social position (supporting indirect selection). These traits thus far explain less than $20 \%$ of the associations between low-SES and mortality $[62,129,204]$. In these studies, both personality and SES still exert independent mortality risks when confounding is controlled. Therefore, despite the presence of indirect selection, the mortality risk of low SES can still be partially offset by adaptive personality traits, and vice versa (a compensatory cumulative model). 


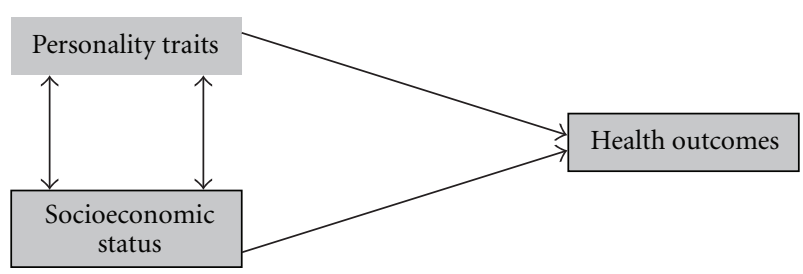

(a)

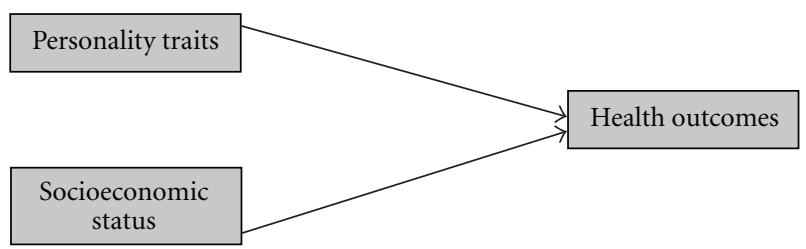

(b)

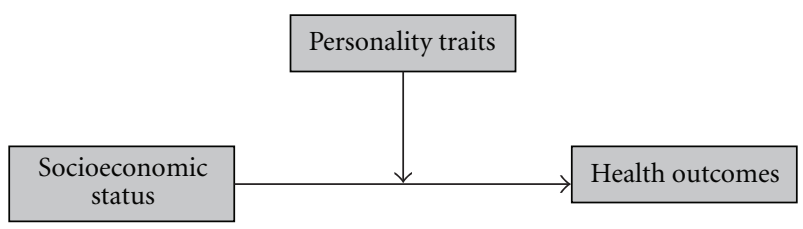

(c)

FIgURE 3: The indirect selection (a), compensatory-cumulative (b), and vulnerability (c) models of the personality-SES interface in health.

Studies are rarely powered to detect interactions between personality and SES however, making it difficult to test the selective vulnerability model adequately. One study did find that mortality risk was reduced by sense of coherence only at higher levels of SES [205], perhaps because such individuals have the resources, in addition to the belief, that they can exert control. Different models may also characterize different personality traits and outcome [32, 206-210]. Another area for further study is the interface between IQ, personality, and SES links to longevity: while mortality risk due to low IQ is partially associated with mortality risk due to low SES, the role of maladaptive personality traits in these associations has been rarely studied [37].

\subsection{Comprehensive Measurement of Personality in Health} Studies. As noted above, there are limitations to both overly general measures of personality that aggregate across several traits (i.e., only some of the content may be relevant to a given health outcome), but also to overly specific traits (i.e., selective focus on one narrow aspect of personality out of context of other traits). The solution to this problem is to employ a personality measurement tool that taps broad personality dimensions in such a way that they can be broken down into narrow, more constituent facets [189]. In other words, one can use a comprehensive measure of the broad Big 5 dimensions to avoid omitting large spans of personality variation, and then statistically disaggregate the composite Big 5 scales into subscales reflecting more specific traits such as hostility and optimism.

A related issue concerns how personality information is used. In addition to constructing dimensional trait scores, it is also possible to examine configuration, or profiles of multiple traits. Classically, such configurations have been called personality types, and more recently joint standing on two Big 5 dimensions at a time has been studied under the moniker of personality styles [52]. Categorizing continuous personality dimensions is often done to examine the effects of a certain trait configurations. However, the resulting categories may reflect relatively heterogeneous groups of people, few of whom resemble the prototype personality profile. A solution to this problem has been to generate personality profiles of interest, then measure each individual's similarity to these profiles on a continuous or dimensional scale [51]. A person's distance to a particular pathologic configuration of multiple traits is then collapsed into one summary dimension. Rather than modeling the association of absolute levels of different traits and mortality, one models similarity to a particularly trait configuration as a risk factor. It is also important to examine nonlinearities and trait interactions $[211,212]$ in predicting mortality, a notion supported by the evolutionary theory that no single trait at high or low levels is likely to be globally adaptive [213].

5.4. Clarifying Mechanisms of Action. Studies to date have often attempted to identify the links between personality and longevity by focusing on health behaviors. While major health behaviors such as poor diet, inactivity, alcohol consumption, and lack of exercise have received general support as mediators of personality-longevity links, three questions remain. First, other health behaviors may play a role, yet are rarely measured. An example is health service utilization, the many determinants of which [214] may include personality [215-217]. Psychological processes at the interface of cognition and behavior, such as health decisionmaking and risk perception, are also correlated with personality [29]. Definitive studies on this have yet to be conducted, however. Second, the increasing inclusion of biomarkers in personality-longevity studies is beginning to illuminate biological pathways such as systemic inflammation $[65,66$, $218,219]$ and artery calcification [220, 221], but many other pathways are theoretically plausible. Particularly intriguing is the possibility that common genetic bases may lead to the associations between some personality phenotypes and longevity [37]. Third, the relative strength of each mediator is far from universally established. Mediational confounding by unobserved pathways may occur in studies that include only one a few mediators, making it difficult to gauge how much personality risk is transmitted through different pathways. Finally, the strength of different pathways is likely to differ across populations. The pathways linking personality to longevity are thus only vaguely understood as a partial function of common health behaviors and largely unknown biological mechanisms. Table 2 lists a number of potential behavioral and biological mechanisms.

Methodologically, an interesting framework has recently been articulated for attaching causal (rather than just prospective associative) interpretations to mediation analyses [222]. A key requirement is control for confounders of the mediation pathway-just as a direct main effect may confounded by unobserved factors, so may a mediated 
TABLE 2: Potential mediators of personality-longevity associations.

\begin{tabular}{|c|c|}
\hline Behavioral & Biological \\
\hline Alcohol use & $\begin{array}{l}\text { Cortisol, markers of HPA Axis } \\
\text { function }\end{array}$ \\
\hline $\begin{array}{l}\text { Cigarette smoking and } \\
\text { tobacco use }\end{array}$ & $\begin{array}{l}\text { Epinephrine/Norepinephrine, } \\
\text { markers of SAM Axis Function }\end{array}$ \\
\hline Physical activity and exercise & Inflammatory Markers \\
\hline BMI & $\begin{array}{l}\text { Adaptive Immune Markers } \\
\text { (Natural Killer Cells, White } \\
\text { Blood Cell Count) }\end{array}$ \\
\hline $\begin{array}{l}\text { Illicit drug use; abuse of } \\
\text { prescription medications }\end{array}$ & Markers of oxidative stress \\
\hline Specific eating habits & Lipids and sclerotic activity \\
\hline Accidents & $\begin{array}{l}\text { Neurodegeneration associated } \\
\text { with HPA axis dysregulation }\end{array}$ \\
\hline Sexual risk behavior & $\begin{array}{l}\text { Markers of metabolic } \\
\text { dysregulation such as insulin } \\
\text { resistance }\end{array}$ \\
\hline $\begin{array}{l}\text { Health risk perception and } \\
\text { evaluation }\end{array}$ & $\begin{array}{l}\text { Genetic Markers of Disease and } \\
\text { Longevity }\end{array}$ \\
\hline Health service use & $\begin{array}{l}\text { Telomere shortening and other } \\
\text { markers of impaired genetic } \\
\text { replication }\end{array}$ \\
\hline $\begin{array}{l}\text { Health care adherence; } \\
\text { communication with health } \\
\text { care providers; trust in health } \\
\text { care delivery system }\end{array}$ & $\begin{array}{l}\text { Mechanisms of pain and somatic } \\
\text { sensitivity }\end{array}$ \\
\hline Sleep behavior; dental hygiene & \\
\hline $\begin{array}{l}\text { Complementary and } \\
\text { Alternative Medicine Use }\end{array}$ & \\
\hline $\begin{array}{l}\text { Health beliefs and somatic } \\
\text { sensitivity }\end{array}$ & \\
\hline $\begin{array}{l}\text { Recruitment of social support; } \\
\text { informal help-seeking }\end{array}$ & \\
\hline
\end{tabular}

effect [222]. Other issues involve the functional form of the mediational pathways (linear versus nonlinear), getting correct standard error estimates for quantities such as the indirect effect, and the complications posed by nonnormal outcome distributions. Equivalent methods for computing indirect effects for linear equations (i.e., the products versus differences of relevant coefficients) are not equivalent with one or more nonlinear (i.e., logistic, survival) models in the mediation system [223]. One solution is to simply use the mediated fraction [224], which is statistically identical to the confounded fraction above but simply assumes that the third variable is a mediator, rather than confounder [225]. Separate examinations of mediating paths in different strata may help identify moderated mediation, reflecting different causal chains in different populations [226].

Understanding pathways between personality and longevity is important if one wishes to conduct targeted interventions in certain at-risk personality populations. To the extent that numerous pathways are operating, however, interventions in at-risk personality populations would need to attempt to modify multiple mediators [227]. Another, possibly more cost-effective, option is to focus on changing the pathogenic personality tendencies in question, which we consider below.

5.5. Integrating Personality into Personalized Medicine. Interest in individual differences in health risk and treatment response has gained great traction over the last decade under the rubric of personalized medicine [228]. The goal of personalized medicine is to individualize care according to the unique characteristics of the patient. Typically, these are demographic or biomedical dimensions of individual differences, such as age, lipid levels, and disease conditions. However, the increasing interest in personalized medicine has really come on the back of GWAS studies, under the rationale that patient risk can be prognosticated with increasing precision as more is learned about the roles of genes in disease [228]. Based on these forecasts, an individual may receive closer monitoring for early signs and symptoms of some disease(s), receive a particular preventive treatment that has benefited others like him or her, and/or have existing treatment adapted to fit better with his or her characteristics [229]. However, personality is conspicuously absent in formulations of personalized medicine. Given the links between personality and health, an obvious opportunity exists for translational research integrating personality phenotype into personalized medicine.

Personality phenotype may complement genetic information in several ways. First, since health is a complex function of behavior and biology, incorporating information from both domains into prediction equations should improve forecasting accuracy. As noted above, only some of the associations between personality and longevity are accounted for by commonly measured health behaviors. This means that personality may provide incremental predictive power in forecasting health, above and beyond the data contained by an individual's health behavior, demographic, or genetic profile. Psychological tests are able to predict behavioral criteria with an accuracy similar to which medical tests predict medical criteria [230], and since health outcomes are multidetermined by biological and behavioral causes, combining assessments of these factors may be cost-effective. Second, genetic risk profiles typically select specific candidate genes that have been shown to predict health outcomes. There is some concern that this approach has not provided the additional predictive power hoped for, particularly relative to the costs of genetic screening [231]. In contrast, personality information can range from quite specific to very general and is relatively low cost given information it may add to health risk profiling. Third, genetic information without data on environmental experiences may weaken the extent to which genes can be said to have implications for health. Personality phenotype reflects the results of gene-environment interaction and encodes environmental variance at a broad behavioral level. Fourth, just as in psychometric measurement, genetic risk profiling can be error-prone [232]. Integrating genotypic with phenotypic measurement may offset the potential cost of measurement error in either by providing supplemental data related to important outcomes. 
An obvious question for translational research is how to incorporate personality trait assessment in standard medical practice, particularly in primary care where most diseases, including the chronic diseases of aging, are managed. Ideas range from including relatively specific screens for traits such as hostility [233], to modern initiatives to incorporate broader personality measures in electronic medical record (EMR) systems. Short Big 5 measures [234, 235] might be used as potential screeners. Individuals scoring above or below empirically identified cut-offs might spark a more thorough, detailed subsequent assessment. This serial testing strategy has proven to be quite effective in medicine and can be thought of as a 2-step algorithm where one minimizes false negatives in the first step, and then weeds out false positives on the second step [236]. Methods exist for identifying cut points for sequential screening scales according to the outcome, scale, and whether one wishes to maximize net sensitivity or specificity from the two-step process [236]. Other methods exist to determine the point at which a continuous risk factor shows the steepest rise for several risks [237].

If indicated, the second, more detailed step of personality assessment in primary care would accomplish three things. First, the additional personality data would increase the accuracy of individual risk forecasting models for outcomes of interest. The idea would be to have a comprehensive measurement of risk for several potentially serious diseases that can be predicted based on combinations of items from the broader personality inventory. Second, a more detailed personality assessment would provide the physician with a wealth of psychosocial data that would otherwise take a long time to gather, preparing the physician for what $\mathrm{s} /$ he may expect behaviorally from a particular patient. This would require assessment infrastructures which interpret the personality data for the physicians, such as computergenerated reports for health practitioners, and available consultation with psychologists. In this sense, personality assessment may be thought of as further automation of the primary care practice of background screening or history taking, which typically relies on self-reported information delivered to the physician during an interview. Formal personality assessment would gather more systematic and broader information, in a more time-effective way, enabling physicians to better know and understand their patients as individuals. Third, this type of information is likely to help guide and tailor treatment planning, enhancing the probability of successful care. In general, personality assessment could improve the provision of patient-centered care because the physicians better understand how to approach and interact with different kinds of patients. The mere presence of these assessment tools in primary care waiting rooms would convey to patients that the provision of high quality health care is not solely about ordering diagnostic tests, arriving at the correct diagnosis, and prescribing appropriate treatments. It is also about expressing concern and empathy and understanding the patient's perspective $[238,239]$, activities that we believe could be facilitated by personality assessment.
Finally, it is important to consider the difference between measuring personality and measuring depressive symptoms in primary care using an instrument like the Patient Health Questionnaire (PHQ)-9. Instruments such as the PHQ-9 are case-finders, identifying prevalent cases of depression, rather than screeners, which identify a pool at-risk for incident depression. Certainly, both activities are important. However, if one wants to engage in any sort of preventive care, people with the risk-factors for outcomes must be identified, not just people already suffering from the undesired outcome itself. Personality assessment thus offers a comprehensive screening strategy for psychosocial health risks, not a casefinding strategy for people with prevalent symptoms for one specific form of psychopathology.

Comprehensive Big 5 measures [240] can be used to develop brief screeners for outcomes of interest using the items on these inventories most predictive of those outcomes. Subsequently, the remainder of the inventory can be administered if a second, more complete assessment is desired. Another approach is to develop highly predictive screeners not embedded in any particular existing instrument, and using these in the first stage, followed by a more comprehensive test. Predictive modeling is an active area of quantitative research and numerous techniques have emerged in the last ten years to facilitate the construction of highly predictive scales [241]. Advances in measurement technology, such as the use of informant report and behavioral measures of personality tendencies, might also be considered. The key is to study these possibilities from a translational viewpoint focused on feasibility of implementation. For instance, health care systems such as Kaiser Permanente and Group Health have begun to incorporate general psychosocial information into electronic medical records.

5.6. Intervening to Change Personality Risk Factors. For some time, it was believed that personality was largely fixed after age 30 [242]. Although there is debate about the degree of naturalistic personality stability $[8,243]$, many now feel that enough documentation of change over the life-course has appeared to justify the study of personality development and change after age 30 [244]. More recent research has shown naturalistic change over the lifespan indicating a pattern of increasing maturity with age, owing to increasing responsibilities such as marriage and childrearing and increases in work responsibility [7]. Others have argued that changes are due largely to the biology of aging [8]. Personality also changes in neural-degenerative diseases such as Alzheimer's [245]. In addition, psychotherapy [242] or pharmacotherapy [246] may alter personality tendencies. Regardless, there is emerging evidence that naturalistic declines in Conscientiousness and Extraversionover at a 10year period are associated with worse self-rated health at follow-up [247], suggesting that personality-related interventions warrant serious consideration.

With respect to traits associated with mortality, psychosocial interventions have successfully reduced hostility [248], Type D traits [116], and deficits in social and emotional functioning in CVD patients [249]; in the latter two studies, patients showed improved 9-year survival rates [116] 
and reductions in sclerosis in the fundus of the eye [249]. Similar psychosocial treatment has been mounted in cancer patients [250], with one study noting small improvement in sclerosis [249] and another enhanced survival time and lymphocyte breast count in breast cancer patients [251]. Studies examining different type of psychosocial intervention generally found health improvements for behavior therapy, which focuses on altering patterns of thoughts and behavior, but not for psychoanalytic therapy, which focused on developing insight into unconscious motivations [251, 252]. As these studies were conducted prior to the advent of reporting standards for clinical trials, it is not surprising that they provided very little information bearing on therapist allegiance or fidelity. Their conclusions must be regarded as tentative. Other studies have noted that selective serotonin reuptake inhibitors (SSRIs) tend to reduce Neuroticism and improve Extraversion [246, 253] in depressed samples, while mindfulness-based stress reduction reduced Neuroticism and improved Conscientiousness in a study of practicing physicians [254]. Another paper showed that Openness to Experience improves as a result of cognitive training in older persons [255]. While these results are suggestive, considerably more data is needed on interventions targeting risky personality traits. A recent National Institute of Aging workgroup on this issue pointed specifically to the need for research on what risk-prone personality tendencies are most apt to change, in whom, and with which intervention modalities. This is an area of emerging research likely to receive considerable attention in the coming decade.

5.7. Quantifying the Public Health Impact of Personality. Another agenda for personality and longevity research is to quantify the health impact of personality using traditional public health metrics. This is particularly important since personality traits, unlike BMI, annual household income or assets, years of education, or other continuous risk factors, have no inherently meaningful metric. As an initial step, traits can be continuously scaled so that a relative risk (RR) reflects, for instance, the difference in risk between people of 1 or 2 standard deviations (SDs) difference in the level of the trait, or the difference in risk between a person at the 25th and 75th percentile of the trait distribution [256]. If personality were height, the difference between a person at the 25th and 75th percentile of a trait would be like the difference between a person $5^{\prime} 6^{\prime \prime}$ tall and one $6^{\prime} 0^{\prime \prime}$ tall, or a difference in personality that would be qualitatively noticeable.

This logic can be extended to common public health metrics such as population attributable risk (PAR) [62]. PAR combines information about the relative risk of a trait such as low conscientiousness, with the prevalence of that trait in the population [257]. This means that traits that have mild effects on an outcome may have a large public health impact if they are relatively common in the population. The converse is also true: a very large conventional effect size for a trait may not necessarily mean it is important in population health, if the level of trait necessary for the effect is relatively rare. The PAR itself is a proportion, ranging between 0 and 1 , which provides the maximum bound by which population mortality can be reduced if the trait is reduced to some reference level in the population. It can be used to pinpoint prevention and intervention avenues that will yield the most benefit to the population, and to derive other epidemiologic estimates such as Number Needed to Treat (NNT), the number of people who must be treated down to a lower level of the trait to prevent one death in the population [257]. PARs are often computed for categorical risk factors, but methods do exist for estimating them based on continuous risk factors such as personality traits [258]. The one study to date estimating hypothetical PARs showed that reducing Neuroticism to -1 SD could decrease population mortality by $13 \%$, controlling for SES [62]. A similar result was observed for raising Conscientiousness to $+1 \mathrm{SD}$ in those also high on Agreeableness. By contrast, eliminating smoking could lead to an $8.8 \%$ reduction, obesity (independent of physical inactivity) a $4.7 \%$ reduction, and inactivity (independent of obesity) a $13 \%$ reduction in population mortality. This illustrates the possibility that intervening to change personality traits may bring somewhat greater benefits because one is treating an underlying cause of multiple mediators (e.g., poor health behaviors) rather than targeting only one or a limited number of the intervening factors [259].

A second way the public health impact of personality may be quantified is by drawing an analogy to aging, which is known to be one of the most potent predictors of longevity. Certain traits are associated with accelerated aging, and the amount of acceleration could be quantified. For instance, one study found that a difference of $1 \mathrm{SD}$ in Conscientiousness and a difference of 8.8 years of age were associated with comparable amounts of physician-assessed medical burden as [192]. Another found that Type D personality was associated with elevations in inflammatory cytokines that was comparable to elevations conferred by 10 years of aging [150]. One caveat is that these studies were cross-sectional, so personality effects were compared to age differences between people, which is not the same as years of ageing within people. However, a 5-year longitudinal followup of older adults in the Conscientiousness study was able to make this distinction [260] and found that -1 SD in Conscientiousness and $-1 \mathrm{SD}$ in agreeableness were equivalent to roughly 4.5 years of chronic disease progression. The authors also placed this in the metric of a common physician-based measure of morbidity, equating it to moderate deterioration in one organ system, or mild deterioration across 2 organ systems [260].

A final public health metric relevant to longevity is the Years of Potential Life Lost (YPLL) associated with, for instance, the 75 th versus 25 th percentile of a personality trait. A crude way to compute this is to set a reference age, such as the average age of survival achieved by those at the mean of Conscientiousness. The age at death of those below the mean is subtracted from this, and averaged. More elaborate computations can be made from parametric survival models that have accurately specified the distribution of survival time [257]. A number of similar measures, including qualityadjusted life years (QALYs) and disability-adjusted life years (DALYs) could also be computed. Such measures would help 


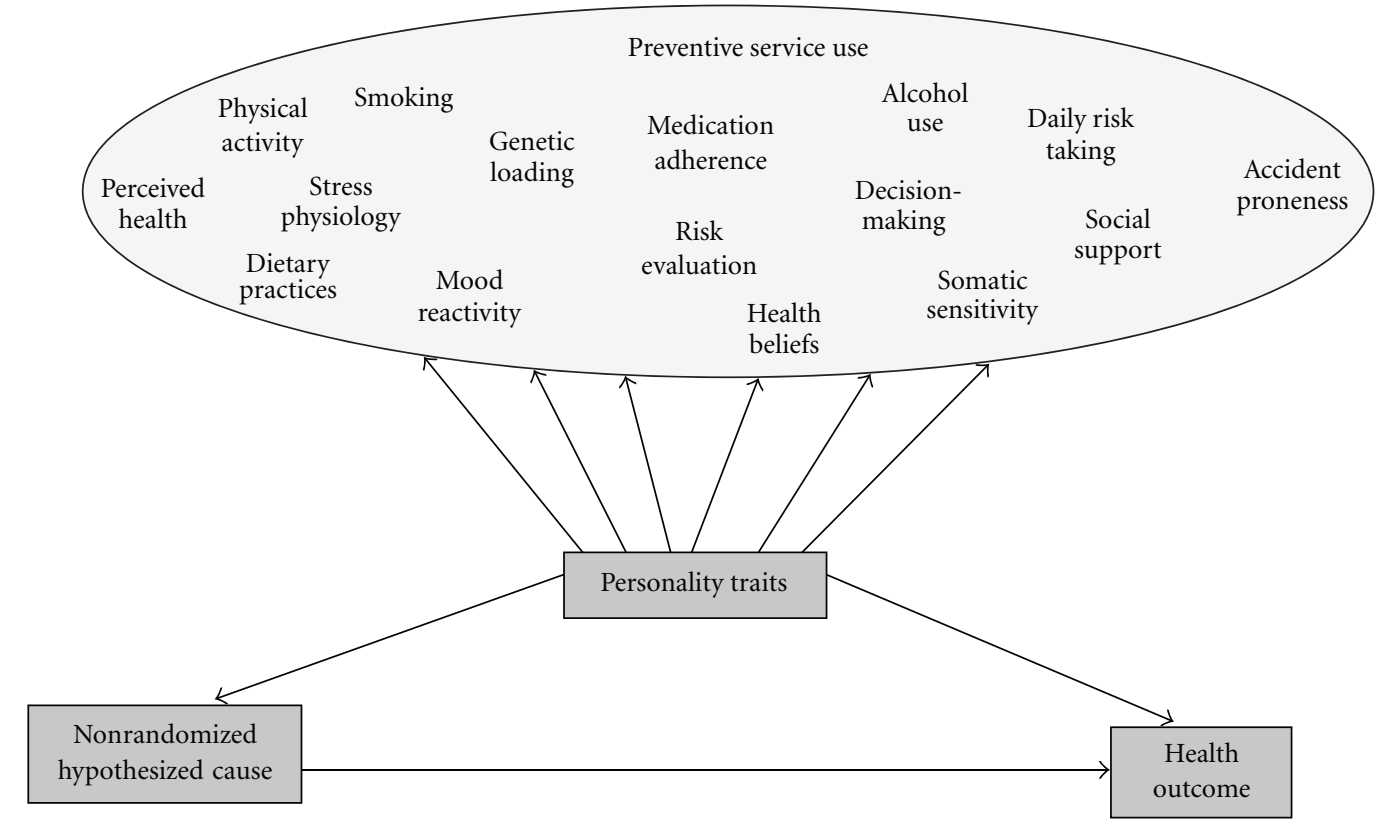

Figure 4: Personality reflects a wide array of unmeasured factors relevant to health that can confound associations between nonrandomized predictors and health outcomes; measuring and adjusting for personality reduces this "healthy subject" bias in a parsimonious fashion.

clarify the individual and population impact of personality traits on longevity.

5.8. Methodologic Uses of Personality to Improve General Research Design. Another implication of personalitylongevity associations lays in the design and conduct of general epidemiologic studies. Numerous biases plague observational studies and to some extent randomized clinical trials [261]. Investigators attempt to reduce and control them, with skepticism over observational studies particularly great after they yielded effect estimates for hormone replacement therapy that were actually the opposite of what subsequent randomized trials showed [262]. Many of these biases are psychological or behavioral in nature and related to personality traits. For instance, volunteer bias, a form of selection bias, is the tendency for well-adjusted, open, and compliant people to participate in studies [261], a function of personality [263,264]. Compliance biases are another concern. Adherence to medication and study drop-out alike appears to be related to personality characteristics [265-267]. The healthy subject effect is a particularly pernicious form of bias in which subjects with generally healthier lifestyles adopt a particular treatment in a nonrandomized study, resulting in unobserved confounding [268]. Personality captures many of the propensities toward healthy lifestyle [269], meaning healthy subject bias may be controlled if personality can be measured. Figure 4 illustrates this concept, which is rooted in recent theories of causal inference [270]. If one can measure a confounder $z$ that captures a wide range of variance in several other unobserved confounders $a-f$, measuring and adjusting for $z$ can remove a large portion of the confounding due to the entire set $a-f$. As a result, use of $z$ may be more cost-effective and analytically tractable in controlling for healthy subject bias. Finally, the healthy survivor effect reflects the tendency for findings in samples of older adults to differ from those in younger samples. As personality is related to longevity, it can be used to better understand and adjust for healthy survivor effects. A detailed discussion of epidemiologic biases can be found in [257], and additional methodological work might study personality measurement as a means of controlling many of these biases.

\section{Conclusions}

Evidence has mounted over the past 30 years implicating personality traits in longevity. The association with longevity of some aspects of personality, such as Conscientiousness, is fairly well established. However, mixed or insufficient data exists for a number of other dispositional factors. Future work will benefit from approaches to personality measurement that allow for both the study of specific traits, and for comprehensive coverage of personality. Our focus has been on longevity. Two related issues are quality of life and the compression of morbidity that has come with extended lifespans over the 20th Century. This refers to the aspiration (already partially achieved) to confine severe disability, lifethreatening disease burden, and other indicators of very poor quality of life to the very end of life, so that most of the extended lifespan can be lived with quality of life. Since considerable research suggests that personality is linked to a number of quality of life measures [122, 271,272], even controlling for objective disease burden [123, 273], personality assessment may play a role in prognosticating and improving quality of life in old age as well. Better understanding 
of the interface between personality and sociostructural influences on longevity is also needed. Personality may also help general health researchers adjust for a number of usually unmeasured behavioral and psychological biases in their studies. Finally, personality traits offer comprehensive information that could be used as personalized medicine begins to gain traction. Translational research is needed to determine how personality information can best be leveraged by personalized medicine.

\section{References}

[1] H. S. Friedman and L. R. Martin, The Longevity Project: Surprising Discoveries for Health and Long Life from the Landmark Eight-Decade Study, Penguin, New York, NY, USA, 2001.

[2] W. Mischel and Y. Shoda, "Integrating dispositions and processing dynamics within a unified theory of personality: the cognitive-affective personality system," in Handbook of Personality: Theory and Research, L. A. Pervin and O. P. John, Eds., pp. 197-218, Guilford Press, New York, NY, USA, 1999.

[3] W. Revelle, Psychology Faculty Profile: William Revelle, 2011, http://www.wcas.northwestern.edu/psych/people/faculty/ faculty_individual_pages/Revelle.htm.

[4] L. R. Goldberg, "The structure of phenotypic personality traits," American Psychologist, vol. 48, no. 1, pp. 26-34, 1993.

[5] R. R. McCrae and P. T. Costa Jr., "Personality trait structure as a human universal," American Psychologist, vol. 52, no. 5, pp. 509-516, 1997.

[6] B. W. Roberts and W. F. DelVecchio, "The rank-order consistency of personality traits from childhood to old age: a quantitative review of longitudinal studies," Psychological Bulletin, vol. 126, no. 1, pp. 3-25, 2000.

[7] B. W. Roberts, K. E. Walton, and W. Viechtbauer, "Patterns of mean-level change in personality traits across the life course: a meta-analysis of longitudinal studies," Psychological Bulletin, vol. 132, no. 1, pp. 1-25, 2006.

[8] P. T. Costa Jr. and R. R. McCrae, "Age changes in personality and their origins: comment on Roberts, Walton, and Viechtbauer (2006)," Psychological Bulletin, vol. 132, no. 1, pp. 26$28,2006$.

[9] S. South and R. F. Krueger, "An interactionist perspective on genetic and environmental contributions to personality," Personality and Social Psychology Compass, vol. 2, no. 2, pp. 929-948, 2008.

[10] A. Terracciano, T. Tanaka, A. R. Sutin et al., "BDNF Val66Met is associated with introversion and interacts with 5-HTTLPR to influence neuroticism," Neuropsychopharmacology, vol. 35, no. 5, pp. 1083-1089, 2010.

[11] A. Terracciano, T. Tanaka, A. R. Sutin et al., "Genome-wide association scan of trait depression," Biological Psychiatry, vol. 68, no. 9, pp. 811-817, 2010.

[12] R. Plomin and A. Caspi, "DNA and personality," European Journal of Personality, vol. 12, no. 5, pp. 387-407, 1998.

[13] R. Plomin and A. Caspi, "Behavioral genetics and personality," in Handbook of Personality: Theory and Research, pp. 251-276, Guilford Press, New York, NY, USA, 1999.

[14] B. W. Roberts and J. J. Jackson, "Sociogenomic personality psychology," Journal of Personality, vol. 76, no. 6, pp. 15231544, 2008.

[15] D. J. Ozer, "Four principles for personality assessment," in Handbook of Personality: Theory and Research, A. Lawrence,
Ed., pp. 671-688, Guilford Press, New York, NY, USA, 2nd edition, 1999.

[16] D. Dunning, C. Heath, and J. M. Suls, "Flawed selfassessment implications for health, education, and the workplace," Psychological Science in the Public Interest, Supplement, vol. 5, no. 3, pp. 69-106, 2004.

[17] R. Bagby, M. B. Marshall, A. S. Bury, J. R. Bacchiochi, and L S. Miller, "Assessing underreporting and overreporting response styles on the MMPI-2," in MMPI-2: A Practitioner's Guide, J. N. Butcher, Ed., pp. 39-69, American Psychological Association, Washington, DC, USA, 2006.

[18] S. R. Millis and C. T. Volinsky, "Assessment of response bias in mild head injury: beyond malingering tests," Journal of Clinical and Experimental Neuropsychology, vol. 23, no. 6, pp. 809-828, 2001.

[19] J. Barnett, "Sensitive questions and response effects: an evaluation," Journal of Managerial Psychology, vol. 13, no. 12, pp. 63-76, 1998.

[20] N. C. Schaeffer, "Asking questions about threatening topics: a selective overview," in The Science of Self Report: Implications for Research and Practice, A. Stone, J. S. Turkkan, C. A. Bachrach, J. B. Jobe, H. S. Kurtzman, and V. S. Cain, Eds., pp. 105-121, Lawrence Erlbaum Associates, Mahway, NJ, USA, 2000.

[21] D. C. Funder, "On the accuracy of personality judgment: a realistic approach," Psychological Review, vol. 102, no. 4, pp. 652-670, 1995.

[22] S. Vazire, "Who knows what about a person? The self-other knowledge asymmetry (SOKA) model," Journal of Personality and Social Psychology, vol. 98, no. 2, pp. 281-300, 2010.

[23] R. E. McGrath, M. Mitchell, B. H. Kim, and L. Hough, "Evidence for response bias as a source of error variance in applied assessment," Psychological Bulletin, vol. 136, no. 3, pp. 450-470, 2010.

[24] R. R. McCrae and P. T. Costa Jr., "Social desirability scales: more substance than style," Journal of Consulting and Clinical Psychology, vol. 51, no. 6, pp. 882-888, 1983.

[25] J. E. Kurtz, S. J. Tarquini, and E. A. Iobst, "Socially desirable responding in personality assessment: still more substance than style," Personality and Individual Differences, vol. 45, no. 1, pp. 22-27, 2008.

[26] H. S. Friedman, "Long-term relations of personality and health: dynamisms, mechanisms, tropisms," Journal of Personality, vol. 68, no. 6, pp. 1089-1107, 2000.

[27] H. S. Friedman, "The multiple linkages of personality and disease," Brain, Behavior, and Immunity, vol. 22, no. 5, pp. 668-675, 2008.

[28] T. Bogg and B. W. Roberts, "Conscientiousness and healthrelated behaviors: a meta-analysis of the leading behavioral contributors to mortality," Psychological Bulletin, vol. 130, no. 6, pp. 887-919, 2004.

[29] K. E. Flynn and M. A. Smith, "Personality and health care decision-making style," Journals of Gerontology-Series B Psychological Sciences and Social Sciences, vol. 62, no. 5, pp. P261-P267, 2007.

[30] S. E. Hampson, J. A. Andrews, M. Barckley, E. Lichtenstein, and M. E. Lee, "Conscientiousness, perceived risk, and riskreduction behaviors: a preliminary study," Health Psychology, vol. 19, no. 5, pp. 496-500, 2000.

[31] S. E. Hampson, J. A. Andrews, M. Barckley, E. Lichtenstein, and M. E. Lee, "Personality traits, perceived risk, and riskreduction behaviors: a further study of smoking and radon," Health Psychology, vol. 25, no. 4, pp. 530-536, 2006. 
[32] J. Neeleman, J. Ormel, and R. V. Bijl, "The distribution of psychiatric and somatic III health: associations with personality and socioeconomic status," Psychosomatic Medicine, vol. 63, no. 2, pp. 239-247, 2001.

[33] J. Neeleman, S. Sytema, and M. Wadsworth, "Propensity to psychiatric and somatic ill-health: evidence from a birth cohort," Psychological Medicine, vol. 32, no. 5, pp. 793-803, 2002.

[34] G. R. Pierce, B. Lakey, I. G. Sarason, and B. R. Sarason, Sourcedbook of Social Support and Personality, Plenum, New York, NY, USA, 1987.

[35] S. C. Segerstrom, "Personality and the immune system: models, methods, and mechanisms," Annals of Behavioral Medicine, vol. 22, no. 3, pp. 180-190, 2000.

[36] S. C. Segerstrom, "Individual differences, immunity, and cancer: lessons from personality psychology," Brain, Behavior, and Immunity, vol. 17, no. 1, pp. S92-S97, 2003.

[37] I. J. Deary, A. W. Weiss, and G. D. Batty, "Intelligence and personality as predictors of illness and death: how researchers in differential psychology and chronic disease epidemiology are collaborating to understand and address health inequalities," Psychological Science in the Public Interests, vol. 11, no. 2, pp. 53-79, 2010.

[38] B. W. Roberts, "Contextualizing personality psychology," Journal of Personality, vol. 75, no. 6, pp. 1071-1082, 2007.

[39] R. D. Conger and M. B. Donnellan, "An interactionist perspective on the socioeconomic context of human development," Annual Review of Psychology, vol. 58, pp. 175-199, 2007.

[40] M. B. Donnellan, K. J. Conger, K. K. McAdams, and T. K. Neppl, "Personal characteristics and resilience to economic hardship and its consequences: conceptual issues and empirical illustrations," Journal of Personality, vol. 77, no. 6, pp. 1645-1676, 2009.

[41] A. Caspi, B. W. Roberts, and R. L. Shiner, "Personality development: stability and change," Annual Review of Psychology, vol. 56, pp. 453-484, 2005.

[42] C. G. DeYoung, "Toward a theory of the big five," Psychological Inquiry, vol. 21, no. 1, pp. 26-33, 2010.

[43] R. R. McCrae and P.T. Costa Jr., "A five-factor yheory of personality," in Handbook of Personality: Theory and Research, L. A. Pervin and O. P. John, Eds., pp. 139-153, Guilford Press, New York, NY, USA, 1999.

[44] G. N. Marshall, C. B. Wortman, R. R. Vickers, J. W. Kusulas, and L. K. Hervig, "The five-factor model of personality as a framework for personality-health research," Journal of Personality and Social Psychology, vol. 67, no. 2, pp. 278-286, 1994.

[45] R. Grossarth-Maticek, J. Bastiaans, and D. T. Kanazir, "Psychosocial factors as strong predictors of mortality from cancer, ischaemic heart disease and stroke: the Yugoslav prospective study," Journal of Psychosomatic Research, vol. 29, no. 2, pp. 167-176, 1985.

[46] S. V. Paunonen and D. N. Jackson, "What is beyond the big five? Plenty!”, Journal of Personality, vol. 68, no. 5, pp. 821$835,2000$.

[47] T. W. Smith, K. Glazer, J. M. Ruiz, and L. C. Gallo, "Hostility, anger, aggressiveness, and coronary heart disease: an interpersonal perspective on personality, emotion, and health," Journal of Personality, vol. 72, no. 6, pp. 1217-1270, 2004.

[48] J. Heckhausen and R. Schulz, "A life-span theory of control," Psychological Review, vol. 102, no. 2, pp. 284-304, 1995.
[49] L. R. Goldberg, "An alternative "Description of Personality": the big-five factor structure," Journal of Personality and Social Psychology, vol. 59, no. 6, pp. 1216-1229, 1990.

[50] D. S. Ones, C. Viswesvaran, and S. Dilchert, "Personality at work: raising awareness and correcting misconceptions," Human Performance, vol. 18, no. 4, pp. 389-404, 2005.

[51] B. Chapman and L. G. Goldberg, "Replicability and 40year predictive power of childhood ARC types," Journal of Personality and Social Psychology. In press.

[52] P.T. Costa Jr. and R. L. Piedmont, "Multivariate assessment: NEO-PI R profiles of madeline G," in Paradigms of Personality Assessment, J. S. Wiggins, Ed., pp. 262-280, Guilford Press, New York, NY, USA, 2003.

[53] B. W. Roberts, O. S. Chernyshenko, S. Stark, and L. R. Goldberg, "The structure of conscientiousness: an empirical investigation based on seven major personality questionnaires," Personnel Psychology, vol. 58, no. 1, pp. 103-139, 2005.

[54] H. Iwasa, Y. Masui, Y. Gondo, H. Inagaki, C. Kawaai, and T. Suzuki, "Personality and all-cause mortality among older adults dwelling in a japanese community: a fiveyear population-based prospective cohort study," American Journal of Geriatric Psychiatry, vol. 16, no. 5, pp. 399-405, 2008.

[55] R. S. Wilson, C. F. Mendes De Leon, J. L. Bienias, D. A. Evans, and D. A. Bennett, "Personality and mortality in old age," Journals of Gerontology-Series B Psychological Sciences and Social Sciences, vol. 59, no. 3, pp. P110-P116, 2004.

[56] P. S. Fry and D. L. Debats, "Perfectionism and the five-factor personality traits as predictors of mortality in older adults," Journal of Health Psychology, vol. 14, no. 4, pp. 513-524, 2009.

[57] A. J. Christensen, S. L. Ehlers, J. S. Wiebe et al., "Patient personality and mortality: a 4-year prospective examination of chronic renal insufficiency," Health Psychology, vol. 21, no. 4, pp. 315-320, 2002.

[58] M. L. Kern and H. S. Friedman, "Do conscientious individuals live longer? A quantitative review," Health Psychology, vol. 27, no. 5, pp. 505-512, 2008.

[59] B.W. Roberts, N. R. Kuncel, R. Shiner, A. Caspi, and L. Goldberg, "The power of personality: the comparative validity of personality traits, socioeconomic Status, and Cognitive Ability for Predicting Important Life Outcomes," Perspectives in Psychological Science, vol. 4, no. 2, pp. 313-346, 2007.

[60] S. C. Segerstrom, J. O. Castañeda, and T. E. Spencer, "Optimism effects on cellular immunity: testing the affective and persistence models," Personality and Individual Differences, vol. 35, no. 7, pp. 1615-1624, 2003.

[61] T. E. Moffitt, L. Arseneault, D. Belsky et al., "A gradient of childhood self-control predicts health, wealth, and public safety," Proceedings of the National Academy of Sciences of the United States of America, vol. 108, no. 7, pp. 2693-2698, 2011.

[62] B. P. Chapman, K. Fiscella, I. Kawachi, and P. R. Duberstein, "Personality, socioeconomic status, and all-cause mortality in the United States," American Journal of Epidemiology, vol. 171, no. 1, pp. 83-92, 2010.

[63] A. Weiss and P. T. Costa Jr., "Domain and facet personality predictors of all-cause mortality among medicare patients aged 65 to 100," Psychosomatic Medicine, vol. 67, no. 5, pp. 724-733, 2005.

[64] L. R. Martin, H. S. Friedman, and J. E. Schwartz, "Personality and mortality risk across the life span: the importance of conscientiousness as a biopsychosocial attribute," Health Psychology, vol. 26, no. 4, pp. 428-436, 2007. 
[65] A. R. Sutin, A. Terracciano, B. Deiana et al., "High Neuroticism and low Conscientiousness are associated with interleukin-6," Psychological Medicine, vol. 40, no. 9, pp. 1485-1493, 2010.

[66] B. P. Chapman, E. van Wijngaarden, C. L. Seplaki, N. Talbot, P. Duberstein, and J. Moynihan, "Openness and conscientiousness predict 34-SSweek patterns of Interleukin6 in older persons," Brain, Behavior, and Immunity, vol. 25, no. 4, pp. 667-673, 2011.

[67] T. B. Harris, L. Ferrucci, R. P. Tracy et al., "Associations of elevated interleukin-6 and C-reactive protein levels with mortality in the elderly," American Journal of Medicine, vol. 106, no. 5, pp. 506-512, 1999.

[68] T. L. Gruenewald, T. E. Seeman, C. D. Ryff, A. S. Karlamangla, and B. H. Singer, "Combinations of biomarkers predictive of later life mortality," Proceedings of the National Academy of Sciences of the United States of America, vol. 103, no. 38, pp. 14158-14163, 2006.

[69] R. R. McCrae, "Openness to experience: expanding the boundaries of factor V," European Journal of Personality, vol. 8, no. 4, pp. 251-272, 1994.

[70] C. G. DeYoung, N. A. Shamosh, A. E. Green, T. S. Braver, and J. R. Gray, "Intellect as distinct from openness: differences revealed by fMRI of working memory," Journal of Personality and Social Psychology, vol. 97, no. 5, pp. 883-892, 2009.

[71] A. Weiss, MJ Adams, A. G. M. S. Widdig, and M. S. Gerald, "Rhesus macaques (Macaca mulatta) as living fossils of hominid personality and subjective well-being," Journal of Comparative Psychology, vol. 135, pp. 72-83, 2011.

[72] C. R. Jonassaint, S. H. Boyle, R. B. Williams, D. B. Mark, I. C. Siegler, and J. C. Barefoot, "Facets of openness predict mortality in patients with cardiac disease," Psychosomatic Medicine, vol. 69, no. 4, pp. 319-322, 2007.

[73] N. A. Turiano, A. Spiro, and D. K. Mcroczek, "Openness to experience and mortality in men: analysis of trait and facets," under review.

[74] G. E. Swan and D. Carmelli, "Curiosity and mortality in aging adults: a 5-year follow-up of the Western Collaborative Group Study," Psychology and Aging, vol. 11, no. 3, pp. 449453, 1996.

[75] P. R. Duberstein, B. P. Chapman, H. A. Tindle et al., "Personality and risk for Alzheimer's disease in adults 72 years of age and older: a 6-year follow-up," Psychology and Aging, vol. 26, no. 2, pp. 351-362, 2011.

[76] A. R. Cappola, Q. L. Xue, L. Ferrucci, J. M. Guralnik, S. Volpato, and L. P. Fried, "Insulin-like growth factor I and interleukin-6 contribute synergistically to disability and mortality in older women," Journal of Clinical Endocrinology and Metabolism, vol. 88, no. 5, pp. 2019-2025, 2003.

[77] R. E. Lucas, E. Diener, A. Grob, E. M. Suh, and L. Shao, "Cross-cultural evidence for the fundamental features of extraversion," Journal of Personality and Social Psychology, vol. 79, no. 3, pp. 452-468, 2000.

[78] W. Revelle, M. S. Humphreys, L. Simon, and K. Gilliand, "The interactive effect of personality, time of day, and caffeine: a test of the arousal model," Journal of Experimental Psychology: General, vol. 109, no. 1, pp. 1-31, 1980.

[79] P. T. Costa Jr. and R. R. McCrae, Revised NEO Personality Inventory and NEO Five Factor Inventory: Professional Manual, Psychological Assessment, Odessa, Fla, USA, 1992.

[80] G. B. Ploubidis and E. Grundy, "Personality and all cause mortality: evidence for indirect links," Personality and Individual Differences, vol. 47, no. 3, pp. 203-208, 2009.
[81] B. A. Shipley, A. Weiss, G. Der, M. D. Taylor, and I. J. Deary, "Neuroticism, extraversion, and mortality in the UK health and lifestyle survey: a 21-year prospective cohort study," Psychosomatic Medicine, vol. 69, no. 9, pp. 923-931, 2007.

[82] H. J. Eysenck, R. Grossarth-Maticek, and B. Everitt, "Personality, stress, smoking, and genetic predisposition as synergistic risk factors for cancer and coronary heart disease," Integrative Physiological and Behavioral Science, vol. 26, no. 4, pp. 309-322, 1991.

[83] B. Chapman, K. Fiscella, P. Duberstein, and I. Kawachi, "Education and smoking: confounding or effect modification by phenotypic personality traits?" Annals of Behavioral Medicine, vol. 38, no. 3, pp. 237-248, 2009.

[84] B. P. Chapman, K. Fiscella, P. Duberstein, M. Coletta, and I. Kawachi, "Can the influence of childhood socioeconomic status on Men's and Women's adult body mass be explained by adult socioeconomic status or personality? Findings from a national sample," Health Psychology, vol. 28, no. 4, pp. 419427, 2009.

[85] R. Grossarth-Maticek and H. J. Eysenck, "Personality, smoking, and alcohol as synergistic risk factors for cancer of the mouth and pharynx," Psychological Reports, vol. 67, no. 3, part 1, pp. 1024-1026, 1990.

[86] W. K. B. Hofstee, B. de Raad, and L. R. Goldberg, "Integration of the Big Five and circumplex approaches to trait structure," Journal of Personality and Social Psychology, vol. 63, no. 1, pp. 146-163, 1992.

[87] S. Read, G. P. Vogler, N. L. Pedersen, and B. Johansson, "Stability and change in genetic and environmental components of personality in old age," Personality and Individual Differences, vol. 40, no. 8, pp. 1637-1647, 2006.

[88] A. Terracciano, C. E. Löckenhoff, A. B. Zonderman, L. Ferrucci, and P. T. Costa Jr., "Personality predictors of longevity: activity, emotional stability, and conscientiousness," Psychosomatic Medicine, vol. 70, no. 6, pp. 621-627, 2008.

[89] R. P. Murray, G. E. Barnes, and O. Ekuma, "Does personality mediate the relation between alcohol consumption and cardiovascular disease morbidity and mortality?" Addictive Behaviors, vol. 30, no. 3, pp. 475-488, 2005.

[90] N. Nakaya, Y. Tsubono, Y. Nishino et al., "Personality and cancer survival: the Miyagi cohort study," British Journal of Cancer, vol. 92, no. 11, pp. 2089-2094, 2005.

[91] G. W. Edmonds, T. Bogg, and B. W. Roberts, "Are personality and behavioral measures of impulse control convergent or distinct predictors of health behaviors?" Journal of Research in Personality, vol. 43, no. 5, pp. 806-814, 2009.

[92] L. D. Kubzansky, P. E. Kubzansky, and J. Maselko, "Optimism and pessimism in the context of health: bipolar opposites or separate constructs?" Personality and Social Psychology Bulletin, vol. 30, no. 8, pp. 943-956, 2004.

[93] L. D. Kubzansky, D. Sparrow, P. Vokonas, and I. Kawachi, "Is the glass half empty or half full? A prospective study of optimism and coronary heart disease in the normative aging study," Psychosomatic Medicine, vol. 63, no. 6, pp. 910-916, 2001.

[94] G. N. Marshall, C. B. Wortman, J. W. Kusulas, L. K. Hervig, and R. R. Vickers, "Distinguishing optimism from pessimism: relations to fundamental dimensions of mood and personality," Journal of Personality and Social Psychology, vol. 62, no. 6, pp. 1067-1074, 1992.

[95] B. H. Brummett, M. J. Helms, W. G. Dahlstrom, and I. C. Siegler, "Prediction of all-cause mortality by the Minnesota 
multiphasic personality inventory optimism-pessimism scale scores: study of a college sample during a 40-year follow-up period," Mayo Clinic Proceedings, vol. 81, no. 12, pp. 15411544, 2006.

[96] B. R. Grossardt, J. H. Bower, Y. E. Geda, R. C. Colligan, and W. A. Rocca, "Pessimistic, anxious, and depressive personality traits predict all-cause mortality: the mayo clinic cohort study of personality and aging," Psychosomatic Medicine, vol. 71, no. 5, pp. 491-500, 2009.

[97] T. Maruta, R. C. Colligan, M. Malinchoc, and K. P. Offord, "Optimists vs pessimists: survival rate among medical patients over a 30-year period," Mayo Clinic Proceedings, vol. 75, no. 2, pp. 140-143, 2000.

[98] R. Schulz, J. Bookwala, M. Scheier, J. E. Knapp, and G. M. Williamson, "Pessimism, age, and cancer mortality," Psychology and Aging, vol. 11, no. 2, pp. 304-309, 1996.

[99] P. J. Allison, C. Guichard, K. Fung, and L. Gilain, "Dispositional optimism predicts survival status 1 year after diagnosis in head and neck cancer patients," Journal of Clinical Oncology, vol. 21, no. 3, pp. 543-548, 2003.

[100] H. Nabi, M. Koskenvuo, A. Singh-Manoux et al., "Low pessimism protects against stroke: the health and social support (hessup) prospective cohort study," Stroke, vol. 41, no. 1, pp. 187-190, 2010.

[101] L. Solberg Nes and S. C. Segerstrom, "Dispositional optimism and coping: a meta-analytic review," Personality and Social Psychology Review, vol. 10, no. 3, pp. 235-251, 2006.

[102] K. Räikkönen, K. A. Matthews, J. D. Flory, J. F. Owens, and B. B. Gump, "Effects of optimism, pessimism, and trait anxiety on ambulatory blood pressure and mood during everyday life," Journal of Personality and Social Psychology, vol. 76, no. 1, pp. 104-113, 1999.

[103] B. Roy, A. V. Diez-Roux, T. Seeman, N. Ranjit, S. Shea, and M. Cushman, "Association of optimism and pessimism with inflammation and hemostasis in the multi-ethnic study of atherosclerosis (MESA)," Psychosomatic Medicine, vol. 72, no. 2, pp. 134-140, 2010.

[104] S. C. Segerstrom, "Optimism, goal conflict, and stressorrelated immune change," Journal of Behavioral Medicine, vol. 24, no. 5, pp. 441-467, 2001.

[105] S. C. Segerstrom, "Optimism and immunity: do positive thoughts always lead to positive effects?" Brain, Behavior, and Immunity, vol. 19, no. 3, pp. 195-200, 2005.

[106] S. C. Segerstrom, "How does optimism suppress immunity? Evaluation of three affective pathways," Health Psychology, vol. 25, no. 5, pp. 653-657, 2006.

[107] S. B. G. Eysenck and H. J. Eysenck, "An improved short questionnaire for the measurement of extraversion and neuroticism," Life Sciences, vol. 3, no. 10, pp. 1103-1109, 1964.

[108] T. A. Judge, A. Erez, J. E. Bono, and C. J. Thoresen, "Are measures of self-esteem, neuroticism, locus of control, and generalized self-efficacy indicators of a common core construct?" Journal of Personality and Social Psychology, vol. 83, no. 3, pp. 693-710, 2002.

[109] B. H. Brummett, M. A. Babyak, R. B. Williams, J. C. Barefoot, P. T. Costa Jr., and I. C. Siegler, "NEO personality domains and gender predict levels and trends in body mass index over 14 years during midlife," Journal of Research in Personality, vol. 40, no. 3, pp. 222-236, 2006.

[110] A. Terracciano and P. T. Costa Jr., "Smoking and the fivefactor Model of personality," Addiction, vol. 99, no. 4, pp. 472-481, 2004.
[111] M. A. Ellenbogen, C. S. Ostiguy, and S. Hodgins, "Intergenerational effects of high neuroticism in parents and their public health significance," American Psychologist, vol. 65, no. 2, pp. 135-136, 2010.

[112] B. B. Lahey, "Public health significance of neuroticism," American Psychologist, vol. 64, no. 4, pp. 241-256, 2009.

[113] K. A. Stamatakis, J. Lynch, S. A. Everson, T. Raghunathan, J. T. Salonen, and G. A. Kaplan, "Self-esteem and mortality: prospective evidence from a population-based study," Annals of Epidemiology, vol. 14, no. 1, pp. 58-65, 2004.

[114] T. A. Murberg, E. Bru, and T. Aarsland, "Personality as predictor of mortality among patients with congestive heart failure: a two-year follow-up study," Personality and Individual Differences, vol. 30, no. 5, pp. 749-757, 2001.

[115] D. K. Mroczek and A. Spiro III, "Personality change influences mortality in older men: research report," Psychological Science, vol. 18, no. 5, pp. 371-376, 2007.

[116] J. Denollet and D. L. Brutsaert, "Reducing emotional distress improves prognosis in coronary heart disease: 9-Year mortality in a clinical trial of rehabilitation," Circulation, vol. 104, no. 17, pp. 2018-2023, 2001.

[117] S. J. Almada, A. B. Zonderman, R. B. Shekelle et al., "Neuroticism and cynicism and risk of death in middle-aged men: the Western Electric study," Psychosomatic Medicine, vol. 53, no. 2, pp. 165-175, 1991.

[118] P. T. Costa Jr. and R. R. McCrae, "Neuroticism, somatic complaints, and disease: is the bark worse than the bite?" Journal of personality, vol. 55, no. 2, pp. 299-316, 1987.

[119] H. S. Friedman, M. L. Kern, and C. A. Reynolds, "Personality and health, subjective well-being, and longevity," Journal of Personality, vol. 78, no. 1, pp. 179-216, 2010.

[120] A. E. Korten, A. F. Jorm, Z. Jiao et al., "Health, cognitive, and psychosocial factors as predictors of mortality in an elderly community sample," Journal of Epidemiology and Community Health, vol. 53, no. 2, pp. 83-88, 1999.

[121] R. Noyes, D. B. Watson, E. M. Letuchy et al., "Relationship between hypochondriacal concerns and personality dimensions and traits in a military population," Journal of Nervous and Mental Disease, vol. 193, no. 2, pp. 110-118, 2005.

[122] A. Jerant, B. Chapman, P. Duberstein, and P. Franks, "Effects of personality on self-rated health in a 1-year randomized controlled trial of chronic illness self-management," British Journal of Health Psychology, vol. 15, no. 2, pp. 321-335, 2010.

[123] B. Chapman, P. Duberstein, and J. M. Lyness, "Personality traits, education, and health-related quality of life among older adult primary care patients," Journals of GerontologySeries B Psychological Sciences and Social Sciences, vol. 62, no. 6, pp. P343-P352, 2007.

[124] A. Antonovsky, Health, Stress, and Coping, Jossey-Bass, San Francisco, Calif, USA, 1979.

[125] P. G. Surtees, N. W. J. Wainwright, and K. T. Khaw, "Sense of coherence, social adversity and mortality," Journal of Psychosomatic Research, vol. 61, no. 3, pp. 376-381, 2006.

[126] P. G. Surtees, N. W. J. Wainwright, R. Luben, K. T. Khaw, and N. E. Day, "Mastery, sense of coherence, and mortality: evidence of independent associations from the EPIC-Norfolk prospective cohort study," Health Psychology, vol. 25, no. 1, pp. 102-110, 2006.

[127] P. G. Surtees, N. W. J. Wainwright, R. Luben, N. J. Wareham, S. A. Bingham, and K. T. Khaw, "Mastery is associated with cardiovascular disease mortality in men and women at apparently low risk," Health Psychology, vol. 29, no. 4, pp. 412-420, 2010. 
[128] P. Surtees, N. Wainwright, R. Luben, K. T. Khaw, and N. Day, "Sense of coherence and mortality in Men and Women in the EPIC-Norfolk United Kingdom prospective cohort study," American Journal of Epidemiology, vol. 158, no. 12, pp. 1202 1209, 2003.

[129] F. V. A. van Oort, F. J. van Lenthe, and J. P. Mackenbach, "Material, psychosocial, and behavioural factors in the explanation of educational inequalities in mortality in the Netherlands," Journal of Epidemiology and Community Health, vol. 59, no. 3, pp. 214-220, 2005.

[130] T. Stürmer, P. Hasselbach, and M. Amelang, "Personality, lifestyle, and risk of cardiovascular disease and cancer: follow-up of population based cohort," British Medical Journal, vol. 332, no. 7554, pp. 1359-1362, 2006.

[131] F. J. Infurma, D. Gerstorf, N. Ram, J. Schupp, and G. G. Wagner, "Long-term antecedents and outcomes of perceived control," Psychology and Aging. In press.

[132] N. C. Hall, J. G. Chipperfield, J. Heckhausen, and R. P. Perry, "Control striving in older adults with serious health problems: a 9-year longitudinal study of survival, health, and well-being," Psychology and Aging, vol. 25, no. 2, pp. 432-445, 2010.

[133] J. Denollet and G. L. Van Heck, "Psychological risk factors in heart disease what type D personality is (not) about," Journal of Psychosomatic Research, vol. 51, no. 3, pp. 465-468, 2001.

[134] J. Denollet, "Personality and coronary heart disease: the typeD scale-16 (DS16)," Annals of Behavioral Medicine, vol. 20, no. 3, pp. 209-215, 1998.

[135] F. De Fruyt and J. Denollet, "Type D personality: a five-factor model perspective," Psychology and Health, vol. 17, no. 5, pp. 671-683, 2002.

[136] J. Denollet, P. De Jonge, A. Kuyper et al., "Depression and type D personality represent different forms of distress in the myocardial iNfarction and depression-intervention trial (MIND-IT)," Psychological Medicine, vol. 39, no. 5, pp. 749756, 2009.

[137] J. Denollet and S. S. Pedersen, "Anger, depression, and anxiety in cardiac patients. The complexity of individual differences in psychological risk," Journal of the American College of Cardiology, vol. 53, no. 11, pp. 947-949, 2009.

[138] J. Denollet, A. A. Schiffer, and V. Spek, "A general propensity to psychological distress affects cardiovascular outcomes: evidence from research on the type $\mathrm{D}$ (distressed) personality profile," Circulation: Cardiovascular Quality and Outcomes, vol. 3, no. 5, pp. 546-557, 2010.

[139] J. Denollet, S. U. Sys, N. Stroobant, H. Rombouts, T. C. Gillebert, and D. L. Brutsaert, "Personality as independent predictor of long-term mortality in patients with coronary heart disease," The Lancet, vol. 347, no. 8999, pp. 417-421, 1996.

[140] S. Pedersen et al., "Increased risk of mortality or myocardial infarction 2 years post-pci in Type D patients treated with sirolimus-eluting stents," Psychology \& Health, vol. 20, pp. 206-207, 2005.

[141] A. A. Schiffer, O. R. F. Smith, S. S. Pedersen, J. W. Widdershoven, and J. Denollet, "Type D personality and cardiac mortality in patients with chronic heart failure," International Journal of Cardiology, vol. 142, no. 3, pp. 230-235, 2010.

[142] A. E. Aquarius, K. G. Smolderen, J. F. Hamming, J. De Vries, P. W. Vriens, and J. Denollet, "Type D personality and mortality in peripheral arterial disease: a pilot study," Archives of Surgery, vol. 144, no. 8, pp. 728-733, 2009.

[143] J. Denollet, Y. Gidron, C. J. Vrints, and V. M. Conraads, "Anger, suppressed anger, and risk of adverse events in patients with coronary artery disease," American Journal of Cardiology, vol. 105, no. 11, pp. 1555-1560, 2010.

[144] A. J. Pelle, S. S. Pedersen, A. A. Schiffer, B. Szabó, J. W. Widdershoven, and J. Denollet, "Psychological distress and mortality in systolic heart failure," Circulation: Heart Failure, vol. 3, no. 2, pp. 261-267, 2010.

[145] J. N. de Voogd, J. B. Wempe, K. Postema et al., "More evidence that depressive symptoms predict mortality in COPD patients: is type D personality an alternative explanation?" Annals of Behavioral Medicine, vol. 38, no. 2, pp. 86-93, 2009.

[146] N. Kupper and J. Denollet, "Type D personality as a prognostic factor in heart disease: assessment and mediating mechanisms," Journal of Personality Assessment, vol. 89, no. 3, pp. 265-276, 2007.

[147] J. Denollet, A. A. Schiffer, M. Kwaijtaal et al., "Usefulness of type D personality and kidney dysfunction as predictors of interpatient variability in inflammatory activation in chronic heart failure," American Journal of Cardiology, vol. 103, no. 3, pp. 399-404, 2009.

[148] V. M. Conraads, J. Denollet, L. S. De Clerck, W. J. Stevens, C. Bridts, and C. J. Vrints, "Type D personality is associated with increased levels of tumour necrosis factor (TNF)- $\alpha$ and TNF$\alpha$ receptors in chronic heart failure," International Journal of Cardiology, vol. 113, no. 1, pp. 34-38, 2006.

[149] J. Denollet, V. M. Conraads, D. L. Brutsaert, L. S. De Clerck, W. J. Stevens, and C. J. Vrints, "Cytokines and immune activation in systolic heart failure: the role of type D personality," Brain, Behavior, and Immunity, vol. 17, no. 4, pp. 304-309, 2003.

[150] J. Denollet, C. J. Vrints, and V. M. Conraads, "Comparing Type D personality and older age as correlates of tumor necrosis factor- $\alpha$ dysregulation in chronic heart failure," Brain, Behavior, and Immunity, vol. 22, no. 5, pp. 736-743, 2008.

[151] N. Kupper, Y. Gidron, J. Winter, and J. Denollet, "Association between type D personality, depression, and oxidative stress in patients with chronic heart failure," Psychosomatic Medicine, vol. 71, no. 9, pp. 973-980, 2009.

[152] K. C. van den Broek, I. Nyklíček, P. H. van der Voort, M. Alings, A. Meijer, and J. Denollet, "Risk of ventricular arrhythmia after implantable defibrillator treatment in anxious type D patients," Journal of the American College of Cardiology, vol. 54, no. 6, pp. 531-537, 2009.

[153] A. J. Pelle, A. A. Schiffer, O. R. Smith, J. W. Widdershoven, and J. Denollet, "Inadequate consultation behavior modulates the relationship between Type D personality and impaired health status in chronic heart failure," International Journal of Cardiology, vol. 142, no. 1, pp. 65-71, 2010.

[154] F. Mols and J. Denollet, "Type D personality among noncardiovascular patient populations: a systematic review," General Hospital Psychiatry, vol. 32, no. 1, pp. 66-72, 2010.

[155] F. Mols and J. Denollet, "Type D personality in the general population: a systematic review of health status, mechanisms of disease, and work-related problems," Health and Quality of Life Outcomes, vol. 8, article no. 9, 2010.

[156] A. J. Pelle, J. Denollet, A. D. Zwisler, and S. S. Pedersen, "Overlap and distinctiveness of psychological risk factors in patients with ischemic heart disease and chronic heart failure: are we there yet?" Journal of Affective Disorders, vol. 113, no. 1-2, pp. 150-156, 2009.

[157] R. F. Krueger, A. Caspi, T. E. Moffitt, P. A. Silva, and R. McGee, "Personality traits are differentially linked to mental disorders: a multitrait-multidiagnosis study of an adolescent 
birth cohort," Journal of Abnormal Psychology, vol. 105, no. 3, pp. 299-312, 1996.

[158] M. Friedman, Type A Behavior: Its Diagnosis and Treatment, Plenum, New York, NY, USA, 1996.

[159] J. C. Barefoot, W. G. Dahlstrom, and R. B. Williams Jr., "Hostility, CHD incidence, and total mortality: a 25-year follow-up study of 255 physicians," Psychosomatic Medicine, vol. 45, no. 1, pp. 59-63, 1983.

[160] R. B. Shekelle, M. Gale, A. M. Ostfeld, and O. Paul, "Hostility, risk of coronary heart disease, and mortality," Psychosomatic Medicine, vol. 45, no. 2, pp. 109-114, 1983.

[161] T. M. Dembroski and P. T. Costa Jr., "Coronary prone behavior: components of the type A pattern and hostility," Journal of Personality, vol. 55, no. 2, pp. 211-235, 1987.

[162] T. M. Dembroski, J. M. MacDougall, P. T. Costa Jr., and G. A. Grandits, "Components of hostility as predictors of sudden death and myocardial infarction in the Multiple Risk Factor Intervention Trial," Psychosomatic Medicine, vol. 51, no. 5, pp. 514-522, 1989.

[163] C. M. Aldwin, A. Spiro, M. R. Levenson, and A. P. Cupertino, "Longitudinal findings from the normative aging study: III. Personality, individual health trajectories, and mortality," Psychology and Aging, vol. 16, no. 3, pp. 450-465, 2001.

[164] M. Koskenvuo, J. Kaprio, R. J. Rose et al., "Hostility as a risk factor for mortality and ischemic heart disease in men," Psychosomatic Medicine, vol. 50, no. 4, pp. 330-340, 1988.

[165] J. C. Barefoot, S. Larsen, L. von der Lieth, and M. Schroll, "Hostility, incidence of acute myocardial infarction, and mortality in a sample of older Danish men and women," American Journal of Epidemiology, vol. 142, no. 5, pp. 477484, 1995.

[166] P. G. Surtees, N. W. J. Wainwright, R. Luben, N. E. Day, and K. T. Khaw, "Prospective cohort study of hostility and the risk of cardiovascular disease mortality," International Journal of Cardiology, vol. 100, no. 1, pp. 155-161, 2005.

[167] C. Iribarren, D. R. Jacobs, C. I. Kiefe et al., "Causes and demographic, medical, lifestyle and psychosocial predictors of premature mortality: the CARDIA study," Social Science and Medicine, vol. 60, no. 3, pp. 471-482, 2005.

[168] E. W. McCranie, L. O. Watkins, J. M. Brandsma, and B. D. Sisson, "Hostility, coronary heart disease (CHD) incidence, and total mortality: lack of association in a 25-year follow-up study of 478 physicians," Journal of Behavioral Medicine, vol. 9, no. 2, pp. 119-125, 1986.

[169] M. D. Hearn, D. M. Murray, and R. V. Luepker, "Hostility, coronary heart disease, and total mortality: a 33-year followup study of university students," Journal of Behavioral Medicine, vol. 12, no. 2, pp. 105-121, 1989.

[170] M. W. Ketterer, J. Huffman, M. A. Lumley et al., "Fiveyear follow-up for adverse outcomes in males with at least minimally positive angiograms: importance of 'denial' in assessing psychosocial risk factors," Journal of Psychosomatic Research, vol. 44, no. 2, pp. 241-250, 1998.

[171] M. W. Kaufmann, J. P. Fitzgibbons, E. J. Sussman et al., "Relation between myocardial infarction, depression, hostility, and death," American Heart Journal, vol. 138, no. 3, pp. 549-554, 1999.

[172] L. A. Chaput, S. H. Adams, J. A. Simon et al., "Hostility predicts recurrent events among postmenopausal women with coronary heart disease," American Journal of Epidemiology, vol. 156, no. 12, pp. 1092-1099, 2002.

[173] J. C. Barefoot, K. A. Dodge, B. L. Peterson, W. G. Dahlstrom, and R. B. Williams, "The Cook-Medley hostility scale: item content and ability to predict survival," Psychosomatic Medicine, vol. 51, no. 1, pp. 46-57, 1989.

[174] J. C. Barefoot, I. C. Siegler, J. B. Nowlin, B. L. Peterson, T. L. Haney, and R. B. Williams, "Suspiciousness, health, and mortality: a follow-up study of 500 older adults," Psychosomatic Medicine, vol. 49, no. 5, pp. 450-457, 1987.

[175] B. K. Houston, M. A. Babyak, M. A. Chesney, G. Black, and D. R. Ragland, "Social dominance and 22-year all-cause mortality in men," Psychosomatic Medicine, vol. 59, no. 1, pp. 5-12, 1997.

[176] S. H. Boyle, R. B. Williams, D. B. Mark et al., "Hostility as a predictor of survival in patients with coronary artery disease," Psychosomatic Medicine, vol. 66, no. 5, pp. 629-632, 2004.

[177] S. A. Everson, J. Kauhanen, G. A. Kaplan et al., "Hostility and increased risk of mortality and acute myocardial infarction: the mediating role of behavioral risk factors," American Journal of Epidemiology, vol. 146, no. 2, pp. 142-152, 1997.

[178] C. Lemogne, H. Nabi, M. Zins et al., "Hostility may explain the association between depressive mood and mortality: evidence from the french gazel cohort study," Psychotherapy and Psychosomatics, vol. 79, no. 3, pp. 164-171, 2010.

[179] L. Musante, J. M. MacDougall, T. M. Dembroski, and P. T. Costa Jr., "Potential for hostility and dimensions of anger," Health Psychology, vol. 8, no. 3, pp. 343-354, 1989.

[180] M. H. Erdelyi, Psychoanalysis: Freud's Cognitive Psychology, W. H. Freeman, New York, NY, USA, 1985.

[181] P. R. Duberstein and J. M. Masling, Psychodynamic Perspectives on Sickness and Health, American Psychological Association, Washington, DC, USA, 2000.

[182] H. J. Eysenck, "Reply to criticisms of the Grossarth-Maticek studies," Psychological Inquiry, vol. 2, no. 3, pp. 297-323, 1991.

[183] K. Hirokawa, C. Nagata, N. Takatsuka, and H. Shimizu, “The relationships of a rationality/antiemotionality personality scale to mortalities of cancer and cardiovascular disease in a community population in Japan," Journal of Psychosomatic Research, vol. 56, no. 1, pp. 103-111, 2004.

[184] J. H. Block and J. Block, "The role of ego control and ego resiliency in the organization of bheavior," in Development of Cognition, Affect, and Social Relations: The Minnesota Symposium on Child Psychology, W. A. Collins, Ed., vol. 13, pp. 39-101, Lawrence Erlbaum Associates, New Jersey, NJ, USA, 1980.

[185] E. Harburg, M. Julius, N. Kaciroti, L. Gleiberman, and M. A. Schork, "Expressive/suppressive anger-coping responses, gender, and types of mortality: a 17-year follow-up (Tecumseh, Michigan, 1971-1988)," Psychosomatic Medicine, vol. 65, no. 4, pp. 588-597, 2003.

[186] M. Petticrew, R. Bell, and D. Hunter, "Influence of psychological coping on survival and recurrence in people with cancer: systematic review," British Medical Journal, vol. 325, no. 7372, pp. 1066-1069, 2002.

[187] M. Watson, J. Davidson-Homewood, J. Haviland, and J. Bliss, "Psychological coping and cancer. Study results should not have been dismissed," BMJ, vol. 326, no. 7389, p. 598; author reply 598, 2003.

[188] H. Nabi, M. Kiviméki, M. Zins et al., "Does personality predict mortality: results from the GAZEL French prospective cohort study," International Journal of Epidemiology, vol. 37, no. 2, pp. 386-396, 2008.

[189] R. F. Krueger, A. Caspi, and T. E. Moffitt, "Epidemiological personology: the unifying role of personality in 
population-based research on problem behaviors," Journal of Personality, vol. 68, no. 6, pp. 967-998, 2000.

[190] G. Saucier, "Replicable item-cluster subcomponents in the NEO five-factor Inventory," Journal of Personality Assessment, vol. 70, no. 2, pp. 263-276, 1998.

[191] B. P. Chapman, "Bandwidth and fidelity on the NEO-five factor inventory: replicability and reliability of Saucier's (1998) item cluster subcomponents," Journal of Personality Assessment, vol. 88, no. 2, pp. 220-234, 2007.

[192] B. P. Chapman, J. M. Lyness, and P. Duberstein, "Personality and medical illness burden among older adults in primary care," Psychosomatic Medicine, vol. 69, no. 3, pp. 277-282, 2007.

[193] A. C. Phillips, G. D. Batty, A. Weiss et al., "Neuroticism, cognitive ability, and the metabolic syndrome: the Vietnam Experience Study," Journal of Psychosomatic Research, vol. 69, no. 2, pp. 193-201, 2010.

[194] A. Weiss, C. R. Gale, G. D. Batty, and I. J. Deary, "Emotionally stable, intelligent men live longer: the Vietnam experience study cohort," Psychosomatic Medicine, vol. 71, no. 4, pp. 385-394, 2009.

[195] L. Seidlitz, Y. Conwell, P. Duberstein, C. Cox, and D. Denning, "Emotion traits in older suicide attempters and non-attempters," Journal of Affective Disorders, vol. 66, no. 23, pp. 123-131, 2001.

[196] E. K. Traupman, T. W. Smith, B. N. Uchino, C. A. Berg, K. K. Trobst, and P. T. Costa Jr., "Interpersonal circumplex octant, control, and affiliation scales for the NEO-PI-R," Personality and Individual Differences, vol. 47, no. 5, pp. 457-463, 2009.

[197] B. P. Chapman, P. R. Duberstein, and J. M. Lyness, "The distressed personality type: replicability and general health associations," European Journal of Personality, vol. 21, no. 7, pp. 911-929, 2007.

[198] L. R. Goldberg, "Doing it all bass-ackwards: the development of hierarchical factor structures from the top down," Journal of Research in Personality, vol. 40, no. 4, pp. 347-358, 2006.

[199] J. P. MacKenbach, "New trends in health inequalities research: now it's personal," The Lancet, vol. 376, no. 9744, pp. 854-855, 2010.

[200] L. F. Berkman and I. Kawachi, Social Epidemiology, Oxford University Press, New York, NY, USA, 2000.

[201] D. Kuh, Y. Ben-Shlomo, J. Lynch, J. Hallqvist, and C. Power, "Life course epidemiology," Journal of epidemiology and community health, vol. 57, no. 10, pp. 778-783, 2003.

[202] J. Gallacher, "Commentary: personality and health inequality: inconclusive evidence for an indirect hypothesis," International Journal of Epidemiology, vol. 37, no. 3, pp. 602-603, 2008.

[203] D. S. Black, Inequalities in Health: The Black Report, Penguin, Harmondsworth, UK, 1988.

[204] H. Nabi, M. Kivimäki, M. G. Marmot et al., "Does personality explain social inequalities in mortality? The French GAZEL cohort study," International Journal of Epidemiology, vol. 37, no. 3, pp. 591-602, 2008.

[205] E. Poppius, L. Tenkanen, M. Hakama, R. Kalimo, and T. Pitkänen, "The sense of coherence, occupation and all-cause mortality in the Helsinki Heart Study," European Journal of Epidemiology, vol. 18, no. 5, pp. 389-393, 2003.

[206] M. E. Lachman and S. L. Weaver, "The sense of control as a moderator of social class differences in health and wellbeing," Journal of Personality and Social Psychology, vol. 74, no. 3, pp. 763-773, 1998.
[207] M. Kivimäki, M. Elovainio, K. Kokko, L. Pulkkinen, M. Kortteinen, and H. Tuomikoski, "Hostility, unemployment and health status: testing three theoretical models," Social Science and Medicine, vol. 56, no. 10, pp. 2139-2152, 2003.

[208] J. W. Lynch, G. A. Kaplan, and J. T. Salonen, "Why do poor people behave poorly? Variation in adult health behaviours and psychosocial characteristics by stages of the socioeconomic lifecourse," Social Science and Medicine, vol. 44, no. 6, pp. 809-819, 1997.

[209] M. G. Marmot, R. Fuhrer, S. L. Ettner, N. F. Marks, L. L. Bumpass, and C. D. Ryff, "Contribution of psychosocial factors to socioeconomic differences in health," Milbank Quarterly, vol. 76, no. 3, pp. 403-448, 1998.

[210] H. Bosma, H. D. van de Mheen, and J. P. Mackenbach, "Social class in childhood and general health in adulthood: questionnaire study of contribution of psychological attributes," British Medical Journal, vol. 318, no. 7175, pp. 18-22, 1999.

[211] T. W. Smith and A. Spiro, "Personality, health, and aging: prolegomenon for the next generation," Journal of Research in Personality, vol. 36, no. 4, pp. 363-394, 2002.

[212] C. R. Cloninger, "How does personality influence mortality in the elderly?" Psychosomatic Medicine, vol. 67, no. 6, pp. 839-840, 2005.

[213] D. Nettle, "The evolution of personality variation in humans and other animals," American Psychologist, vol. 61, no. 6, pp. 622-631, 2006.

[214] R. M. Andersen, "Revisiting the behavioral model and access to medical care: does it matter?" Journal of Health and Social Behavior, vol. 36, no. 1, pp. 1-10, 1995.

[215] J. G. Chipperfield and L. Greenslade, "Perceived control as a buffer in the use of health care services," Journals of Gerontology-Series B Psychological Sciences and Social Sciences, vol. 54, no. 3, pp. P146-P154, 1999.

[216] R. D. Goodwin, C. W. Hoven, J. S. Lyons, and M. B. Stein, "Mental health service utilization in the United States. The role of personality factors," Social Psychiatry and Psychiatric Epidemiology, vol. 37, no. 12, pp. 561-566, 2002.

[217] B. P. Chapman, K. Fiscella, I. Kawachi, and P. R. Duberstein, "Personality traits predict emergency department utilization over three years in older patients," American Journal of Geriatric Psychiatry, vol. 17, pp. 526-535, 2009.

[218] A. R. Sutin, P. T. Costa Jr., M. Uda, L. Ferrucci, D. Schlessinger, and A. Terracciano, "Personality and metabolic syndrome," Age, vol. 32, no. 4, pp. 513-519, 2010.

[219] B. P. Chapman, A. Khan, M. Harper et al., "Gender, race/ethnicity, personality, and interleukin-6 in urban primary care patients," Brain, Behavior, and Immunity, vol. 23, no. 5, pp. 636-642, 2009.

[220] A. R. Sutin, A. Scuteri, E. G. Lakatta et al., "Trait antagonism and the progression of arterial thickening: women with antagonistic traits have similar carotid arterial thickness as men," Hypertension, vol. 56, no. 4, pp. 617-622, 2010.

[221] A. R. Sutin, A. Terracciano, B. Deiana et al., "Cholesterol, triglycerides, and the five-factor model of personality," Biological Psychology, vol. 84, no. 2, pp. 186-191, 2010.

[222] K. Imai, L. Keele, and D. Tingley, "A general approach to causal mediation analysis," Psychological Methods, vol. 15, no. 4, pp. 309-334, 2010.

[223] B. Huang, S. Sivaganesan, P. Succop, and E. Goodman, "Statistical assessment of mediational effects for logistic mediational models," Statistics in Medicine, vol. 23, no. 17, pp. 2713-2728, 2004. 
[224] J. S. Kaufman, R. F. MacLehose, S. Kaufman, and S. Greenland, "The mediation proportion," Epidemiology, vol. 16, no. 5, p. 710, 2005.

[225] D. P. MacKinnon, J. L. Krull, and C. M. Lockwood, "Equivalence of the mediation, confounding and suppression effect," Prevention Science, vol. 1, no. 4, pp. 173-181, 2000.

[226] K. J. Preacher, D. D. Rucker, and A. F. Hayes, "Addressing moderated mediation hypotheses: theory, methods, and prescriptions," Multivariate Behavioral Research, vol. 42, no. 1, pp. 185-227, 2007.

[227] NIH, NIH Science of Behavior Change Meeting Summary, 2009.

[228] M. A. Hamburg and F. S. Collins, "The path to personalized medicine," The New England Journal of Medicine, vol. 363, no. 4, pp. 301-304, 2010.

[229] G. S. Ginsburg and H. F. Willard, "Genomic and personalized medicine: foundations and applications," Translational Research, vol. 154, no. 6, pp. 277-287, 2009.

[230] G. J. Meyer, S. E. Finn, L. D. Eyde et al., "Psychological testing and psychological assessment: a review of evidence and issues," American Psychologist, vol. 56, no. 2, pp. 128-165, 2001.

[231] T. A. Manolio, "Genomewide association studies and assessment of risk of disease," The New England Journal of Medicine, vol. 363, no. 21, pp. 2076-2077, 2010.

[232] P. C. Ng, S. S. Murray, S. Levy, and J. C. Venter, "An agenda for personalized medicine," Nature, vol. 461, no. 7265, pp. 724-726, 2009.

[233] L. D. Kubzansky, I. Kawachi, and D. Sparrow, "Socioeconomic status, hostility, and risk factor clustering in the normative aging study: any help from the concept of allostatic load?" Annals of Behavioral Medicine, vol. 21, no. 4, pp. 330-338, 1999.

[234] S. D. Gosling, P. J. Rentfrow, and W. B. Swann Jr., "A very brief measure of the Big-Five personality domains," Journal of Research in Personality, vol. 37, no. 6, pp. 504-528, 2003.

[235] M. B. Donnellan, F. L. Oswald, B. M. Baird, and R. E. Lucas, "The Mini-IPIP scales: tiny-yet-effective measures of the Big Five factors of personality," Psychological Assessment, vol. 18, no. 2, pp. 192-203, 2006.

[236] M. Woodward, Epidemiology: Study Design and Data Analysis, Chapman \& Hall, New York, NY, USA, 2nd edition, 2005.

[237] L. Ryan, "Quantitative risk assessment for developmental toxicity," Biometrics, vol. 48, no. 1, pp. 163-174, 1992.

[238] I. O. Medicine, Crossing the Quality Chasm: A New Health System for the 21st Century, The National Academies Press, Washington, DC, USA, 2001.

[239] R. M. Epstein, P. Franks, K. Fiscella et al., "Measuring patientcentered communication in Patient-Physician consultations: theoretical and practical issues," Social Science and Medicine, vol. 61, no. 7, pp. 1516-1528, 2005.

[240] B. De Raad and M. Perugini, Big Five Assessment, Hogrefe \& Huber Publishers, Toronto, Canada, 2002.

[241] T. Hastie, R. Tibshirani, and J. Friedman, The Elements of Statistical Learning: Data Mining, Inference, and Prediction, Springer, New York, NY, USA, 2nd edition, 2009.

[242] P. T. Costa Jr. and R. R. McCrae, Personality in Adulthood: A Five Factor Theory Perspective, Guilford Press, New York, NY, USA, 2nd edition, 2033.

[243] B. W. Roberts, K. E. Walton, and W. Viechtbauer, "Personality traits change in adulthood: reply to Costa and McCrae (2006)," Psychological Bulletin, vol. 132, no. 1, pp. 29-32, 2006.
[244] G. W. Edmonds, "Is character fate, or is there hope to change my personality yet?" Social and Personality Psychology Compass, vol. 2, no. 1, pp. 399-413, 2008.

[245] J. M. Duchek, D. A. Balota, M. Storandt, and R. Larsen, "The power of personality in discriminating between healthy aging and early-stage Alzheimer's disease," Journals of Gerontology-Series B Psychological Sciences and Social Sciences, vol. 62, no. 6, pp. P353-P361, 2007.

[246] T. Z. Tang, R. J. DeRubeis, S. D. Hollon, J. Amsterdam, R. Shelton, and B. Schalet, "Personality change during depression treatment: a placebo-controlled trial," Archives of General Psychiatry, vol. 66, no. 12, pp. 1322-1330, 2009.

[247] N. A. Turiano, L. M. Pitzer, and C. Armour, "Personality trait level and change as predictors of health outcomes: findings from a national study of Americans (MIDUS)," Journal of Gerontology: Psychological Science. In press.

[248] Y. Gidron, K. Davidson, and I. Bata, "The short-term effects of a hostility-reduction intervention on male coronary heart disease patients," Health Psychology, vol. 18, no. 4, pp. 416420, 1999.

[249] R. Grossarth-Maticek, H. Eysenck, G. Gallasch, H. Vetter, and R. Frentzel-Beyme, "Changes in degree of sclerosis as a function of prophylactic treatment in cancer-prone and CHD-prone probands," Behaviour Research and Therapy, vol. 29, no. 4, pp. 343-351, 1991.

[250] R. Grossarth-Maticek, "Social Psychotherapy and course of the disease. First experiences with cancer patients," Psychotherapy and Psychosomatics, vol. 33, no. 3, pp. 129-138, 1980.

[251] R. Grossarth-Maticek and H. J. Eysenck, "Length of survival and lymphocyte percentage in women with mammary cancer as a function of psychotherapy," Psychological Reports, vol. 65, no. 1, pp. 315-321, 1989.

[252] R. Grossarth-Maticek and H. J. Eysenck, "Prophylactic effects of psychoanalysis on cancer-prone and coronary heart disease-prone probands, as compared with control groups and behaviour therapy groups," Journal of Behavior Therapy and Experimental Psychiatry, vol. 21, no. 2, pp. 91-99, 1990.

[253] P. T. Costa Jr., R. M. Bagby, J. H. Herbst, and R. R. McCrae, "Personality self-reports are concurrently reliable and valid during acute depressive episodes," Journal of Affective Disorders, vol. 89, no. 1-3, pp. 45-55, 2005.

[254] M. S. Krasner, R. M. Epstein, H. Beckman et al., "Association of an educational program in mindful communication with burnout, empathy, and attitudes among primary care physicians," JAMA, vol. 302, no. 12, pp. 1284-1293, 2009.

[255] J. J. Jackson, P. L. Hill, B. R. Payne, B. W. Roberts, and A. L. Stine-Morrow, "Can an old dog learn (and want to experience) new tricks? Cognitive training increases openness to experience in older adults," under review.

[256] F. E. Harrell Jr., Regression Modeling Strategies, Springer, New York, NY, USA, 2001.

[257] K. J. Rothman, S. Greenland, and T. L. Lash, Modern Epidemiology, Lippincott Williams \& Wilkins, Philadelphia, $\mathrm{Pa}$, USA, 3rd edition, 2008.

[258] S. Greenland and K. Drescher, "Maximum likelihood estimation of the attributable fraction from logistic models," Biometrics, vol. 49, no. 3, pp. 865-872, 1993.

[259] N. N. I. O. Health, NIH Science of Behavior Change Meeting Summary, National Institutes of Heath, Bethesda, Md, USA, 2009. 
[260] B. P. Chapman, B. W. Roberts, J. M. Lyness, and P. R. Duberstein, "Personality trait predictors of physicianassessed illness burden over 4 year in older adults," American Journal of Geriatric Psychiatry, In press.

[261] T. L. Lash, M. P. Fox, and K. Fink, Applying Quantitative Bias Analysis to Epidemiologic Data, Springer, New York, NY, USA, 2009.

[262] J. P. A. Ioannidis, "Why most published research findings are false," PLoS Medicine, vol. 2, no. 8, pp. 0696-0701, 2005.

[263] J. A. Walsh and M. M. Nash, "Personality characteristics of volunteers for medical research," Criminal Justice and Behavior, vol. 5, no. 2, pp. 99-116, 1978.

[264] J. E. Lönnqvist, S. Paunonen, M. Verkasalo, S. Leikas, A. Tuulio-Henriksson, and J. Lönnqvist, "Personality characteristics of research volunteers," European Journal of Personality, vol. 21, no. 8, pp. 1017-1030, 2007.

[265] A. J. Christensen, "Patient-by-treatment context interaction in chronic disease: a conceptual framework for the study of patient adherence," Psychosomatic Medicine, vol. 62, no. 3, pp. 435-443, 2000.

[266] A. Jerant, E. P. Chapman, P. Duberstein, and P. Franks, "Is personality a key predictor of missing study data? An analysis from a randomized controlled trial," Annals of Family Medicine, vol. 7, no. 2, pp. 148-156, 2009.

[267] A. Jerant, B. Chapman, P. Duberstein, J. Robbins, and P. Franks, "Personality and medication non-adherence among older adults enrolled in a six-year trial," British Journal of Health Psychology, vol. 16, no. 1, pp. 151-169, 2011.

[268] J. P. A. Ioannidis, A. B. Haidich, M. Pappa et al., "Comparison of evidence of treatment effects in randomized and nonrandomized studies," JAMA, vol. 286, no. 7, pp. 821-830, 2001.

[269] G. Edmonds, Personality and the Healthy Lifestyle as Predictors of Physical Health: Can the Healthy Lifestyle be Explained by Personality? Department of Psychology, University of Illinois at Urbana-Champaign, Urbana, Ill, USA, 2009.

[270] J. Pearl, "An introduction to causal inference," International Journal of Biostatistics, vol. 6, no. 2, article 7, 2010.

[271] A. Jerant, B. Chapman, P. Duberstein, and P. Franks, "Effects of personality on self-rated health in a 1-year randomized controlled trial of chronic illness self-management," British Journal of Health Psychology, vol. 15, no. 2, pp. 321-335, 2010.

[272] B. P. Chapman, P. Franks, P. R. Duberstein, and A. Jerant, "Differences between individual and societal health state valuations: any link with personality?" Medical Care, vol. 47, no. 8, pp. 902-907, 2009.

[273] B. P. Chapman, P. R. Duberstein, S. Sörensen, and J. M. Lyness, "Personality and perceived health in older adults: the five factor model in primary care," Journals of GerontologySeries B Psychological Sciences and Social Sciences, vol. 61, no. 6, pp. P362-P365, 2006. 


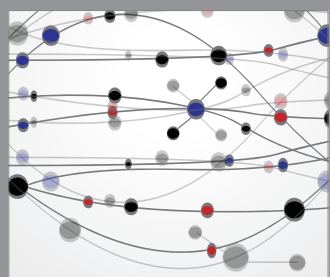

The Scientific World Journal
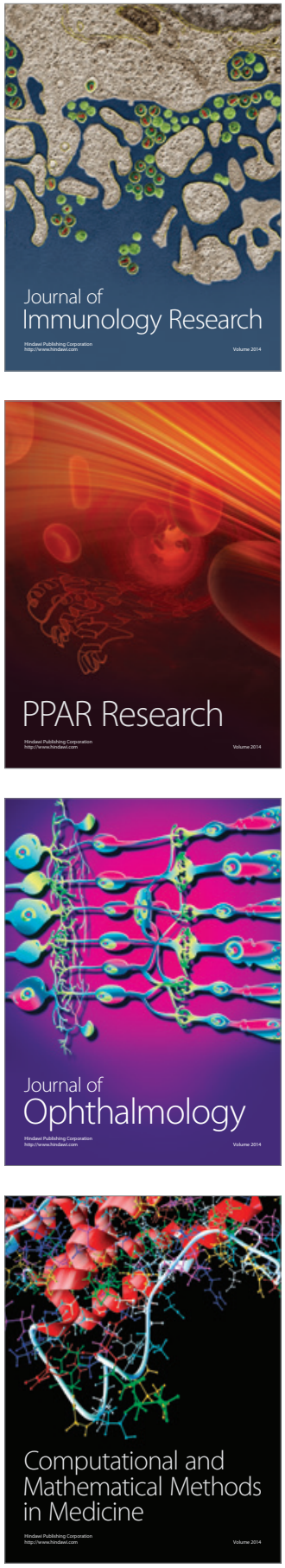

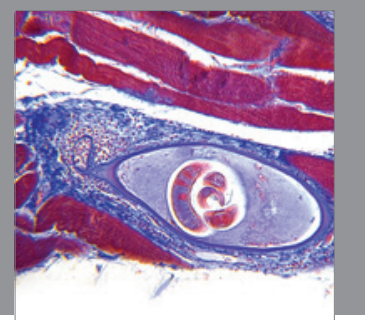

Gastroenterology

Research and Practice
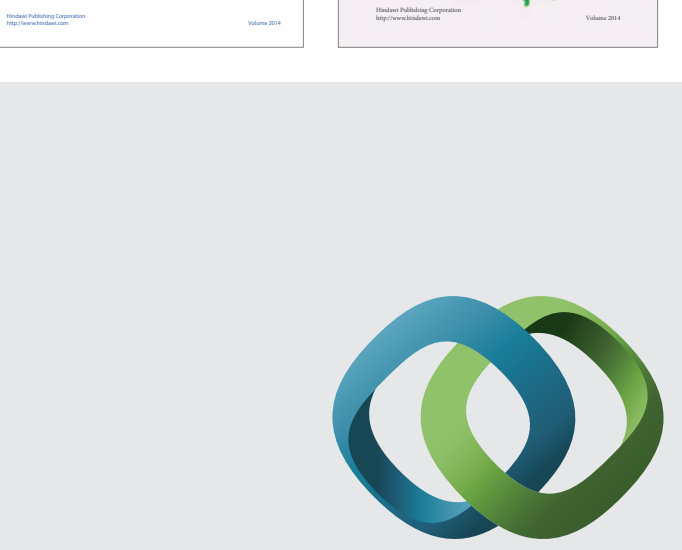

\section{Hindawi}

Submit your manuscripts at

http://www.hindawi.com
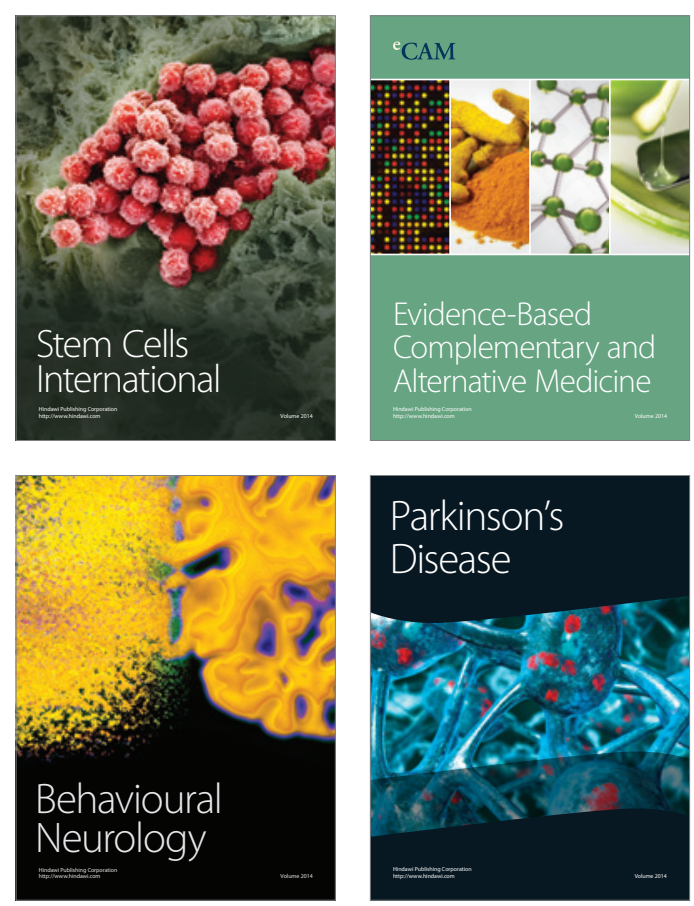

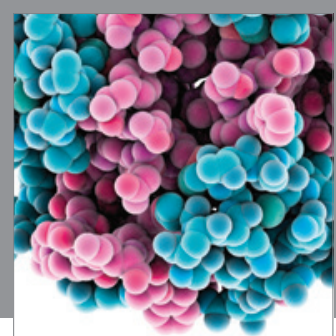

Journal of
Diabetes Research

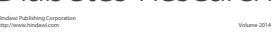

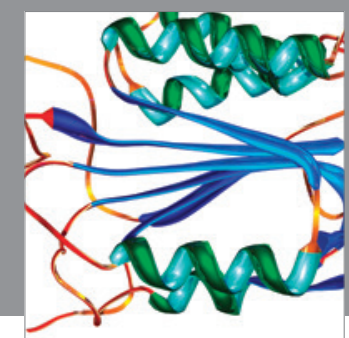

Disease Markers
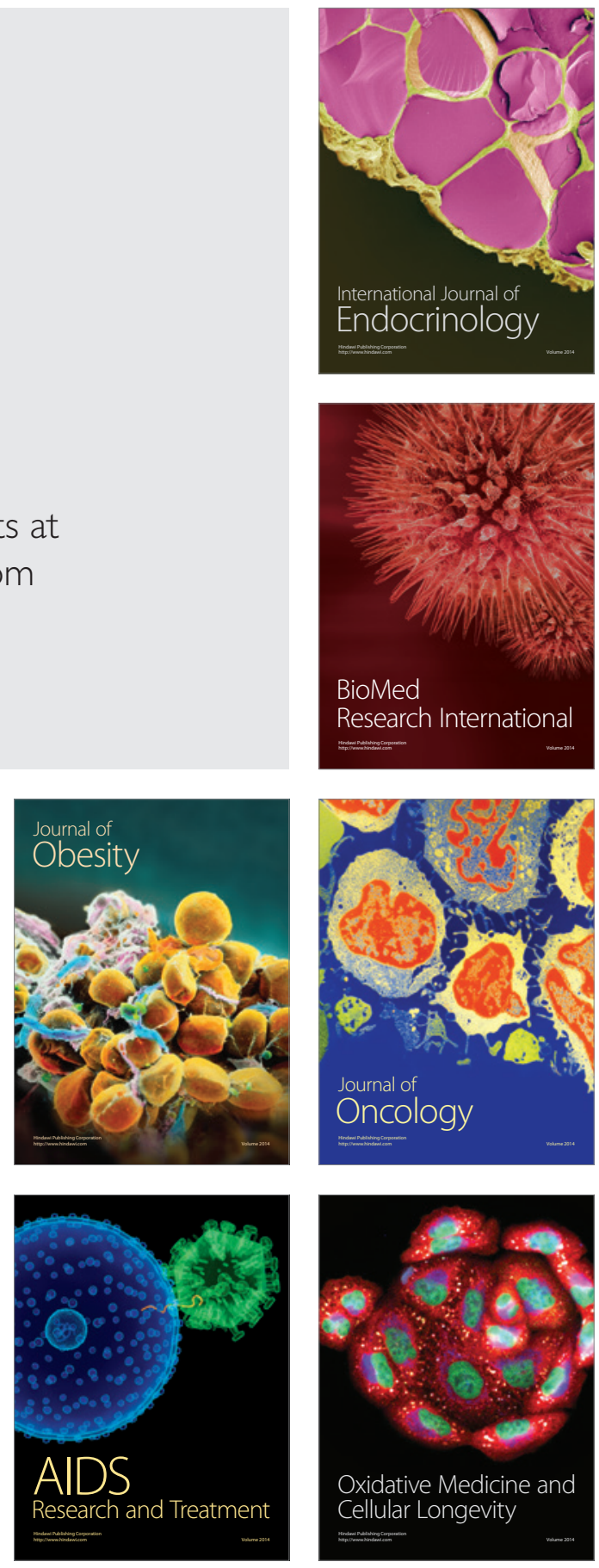